\title{
Construction and Building Materials
}

\section{Performance-Related and Rheological Characterisation of Natural Rubber Modified Bitumen}

--Manuscript Draft--

\begin{tabular}{|c|c|}
\hline Manuscript Number: & CONBUILDMAT-D-20-03087R2 \\
\hline Keywords: & $\begin{array}{l}\text { Natural Rubber; Bitumen Modification; Fatigue; Rutting; Fracture; Performance; } \\
\text { Rheology. }\end{array}$ \\
\hline Corresponding Author: & $\begin{array}{l}\text { Juan Sebastián Carvajal Muñoz, MSc, Ph.D. Candidate } \\
\text { Universidad del Norte } \\
\text { Barranquilla, COLOMBIA }\end{array}$ \\
\hline First Author: & Jarurat Wititanapanit, M.Sc. \\
\hline \multirow[t]{3}{*}{ Order of Authors: } & Jarurat Wititanapanit, M.Sc. \\
\hline & Juan Sebastián Carvajal Muñoz, MSc, Ph.D. Candidate \\
\hline & Gordon Airey, M.Sc., Ph.D. \\
\hline
\end{tabular}


September $8^{\text {th }} 2020$

Respected

Dr. Dimitrios Aggelis

Editor

Construction and Building Materials, ELSEVIER

Dear Dr. Aggelis:

After the comments raised by the reviewers, I kindly resubmit for evaluation the updated version of the scientific article entitled: "Performance-Related and Rheological Characterisation of Natural Rubber Modified Bitumen" by Jarurat Wititanapanit, Juan S. Carvajal and Gordon Airey. Likewise, through this communication I would like to inform you that this article is original in nature and that it has not been and will not be presented to any other journal or academic event. In the same way I allow myself to confirm that the authors of this article assume collective responsibility for the information contained in the manuscript.

The following is the information of the authors of the article:

\section{Jarurat Wititanapanit}

Master of Science, Researcher, Department of Rural Roads, Ministry of Transport, Bangkhen, Bangkok, Thailand

Juan S. Carvajal-Munoz (Corresponding author: evxjsc@nottingham.ac.uk )

Ph.D. Candidate, Nottingham Transportation Engineering Centre (NTEC), University of Nottingham, United Kingdom. Professor on academic leave, Department of Civil and Environmental Engineering, Universidad del Norte,

Barranquilla, Colombia.

Gordon Airey

Ph.D. Professor and Director of the Nottingham Transportation Engineering Centre (NTEC), University of Nottingham, United Kingdom

It's worth mentioning that both of my affiliations (University of Nottingham (UK), and Universidad del Norte (Colombia)) should appear on the manuscript for all stages of review and for publication if the manuscript is accepted.

I appreciate your kind attention to this letter and the attached manuscript.

Sincerely,

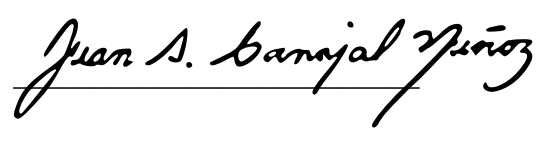

Juan S. Carvajal-Muñoz

PhD Student, Nottingham Transportation Engineering Centre (NTEC). The University of Nottingham

Google Scholar $\underline{\text { ResearchGate LinkedIn }}$

E-mail: juan.carvajalmunoz@nottingham.ac.uk

Address: NTEC, Pavement Research Building, University Park, Nottingham, NG72RD 
Nottingham, April $9^{\text {th }} 2020$

Respected

Dr. Dimitrios Aggelis

Editor

Construction and Building Materials, ELSEVIER

Dear Dr. Aggelis:

Hereby I kindly submit for evaluation the scientific article entitled: "Performance-Related and Rheological Characterisation of Natural Rubber Modified Bitumen" by Jarurat Wititanapanit, Juan S. Carvajal and Gordon Airey. Likewise, through this communication I would like to inform you that this article is original in nature and that it has not been and will not be presented to any other journal or academic event. In the same way I allow myself to confirm that the authors of this article assume collective responsibility for the information contained in the manuscript.

The following is the information of the authors of the article:

\section{Jarurat Wititanapanit}

Master of Science, Researcher, Department of Rural Roads, Ministry of Transport, Bangkhen, Bangkok, Thailand

Juan S. Carvajal-Munoz (Corresponding author: evxjsc@nottingham.ac.uk )

Ph.D. Candidate, Nottingham Transportation Engineering Centre (NTEC), University of Nottingham, United Kingdom. Professor on academic leave, Department of Civil and Environmental Engineering, Universidad del Norte,

Barranquilla, Colombia.

Gordon Airey

Ph.D. Professor and Director of the Nottingham Transportation Engineering Centre (NTEC), University of Nottingham, United Kingdom

It's worth mentioning that both of my affiliations (University of Nottingham (UK), and Universidad del Norte (Colombia)) should appear on the manuscript for all stages of review and for publication if the manuscript is accepted.

I appreciate your kind attention to this letter and the attached manuscript.

Sincerely,

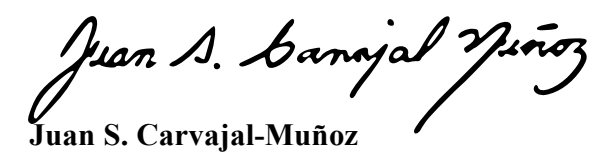

PhD Student, Nottingham Transportation Engineering Centre (NTEC). The University of Nottingham

Google Scholar ResearchGate LinkedIn

E-mail: juan.carvajalmunoz@,nottingham.ac.uk

Address: NTEC, Pavement Research Building, University Park, Nottingham, NG72RD 


\title{
Performance-Related and Rheological Characterisation of Natural Rubber Modified Bitumen
}

\begin{abstract}
This paper is motivated by the limited research available evaluating the comprehensive effects of natural rubber bitumen modification (NR) for pavement applications. A detailed laboratory programme was carried out to evaluate the influence of NR on the high-intermediate-low temperature performance, including rheological characterisations and performance-related tests (fatigue cracking, thermal cracking, fracture and permanent deformation resistance). The main findings indicate some beneficial effects of NR on the performance-related response for fatigue and permanent deformation. Additional benefits were observed regarding the fracture strength and the thermal cracking resistance $\left(\Delta T_{c}\right)$. The viscoelastic effects of NR produced significant changes in the rheological properties of the base bitumen. Overall, the use of NR at a concentration of up to $7 \%$ by weight of bitumen proved to be a reasonable option for use in pavement applications, having more substantial benefits in tropical regions in agreement with its predominant effects on the bitumen modification at intermediate-to-high temperature conditions.
\end{abstract}

Keywords: Natural Rubber; Bitumen Modification; Fatigue; Rutting; Fracture; Performance; Rheology.

\section{Introduction}

Natural rubber (NR) is a material produced from native trees (Hevea brasiliensis) in South Asia, which is commonly used as a manufactured product either solely or combined with other materials in various industries (e.g., automobile, textile, insulating membranes, adhesives, footwear and construction). NR is widely used as a consequence of its high stretch ratio (i.e., high ductile response or elasticity), its ability to withstand external loading (i.e., permanent deformation resistance) and the high water resistance. In spite of being extensively produced and commercialised from the early 70's, the current bulging stocks of NR in Southeast Asian countries and the trends of decreasing trade price are gradually encouraging governments and environmental agencies to sought for alternative applications in road infrastructure projects [1,2]. Similarly, the pressing environmental needs for recycling demands the selection of environmentally friendly alternatives as surrogates of finite natural resources, which supposes the incorporation of waste materials such as recycled tyre rubber [36] for road infrastructure applications,. At this respect, from the late 80 's to the early 90 's, research studies have assessed the effects of waste rubber (typically reclaimed from tyres) on bituminous mixtures incorporating multiple approaches and techniques [7-9]. For instance, [10] provided practical guidelines for the design, construction and maintenance of tyre-rubber modified mixtures. More recently, [5] presented a comprehensive 
literature review of the various benefits associated with the use of recycled tyre-rubber (RTR) with a critical 
Table 1. Natural rubber properties.

1

\begin{tabular}{|c|c|c|c|}
\hline Parameters & Unit & Specification & Results \\
\hline $\begin{array}{l}\text { Total solids content } \\
\text { (TSC) }\end{array}$ & $\%$ by mass & $61.50 \mathrm{~min}$. & 61.80 \\
\hline Dry rubber content & $\%$ by mass & $60.00 \mathrm{~min}$. & 60.21 \\
\hline $\mathrm{pH}$ value at $25.4^{\circ} \mathrm{C}$ & -- & 11 max. & 10.48 \\
\hline $\begin{array}{l}\text { Pottassium Hidroxide } \\
\text { Number }(\mathrm{KOH})\end{array}$ & $\%$ by mass & 0.70 max. & 0.69 \\
\hline $\begin{array}{l}\text { Alkalinity (as ammonia } \\
\text { on total weight) }\end{array}$ & $\%$ by mass & $0.65-0.75$ & 0.68 \\
\hline Non rubber content & $\%$ by mass & 1.70 max. & 1.59 \\
\hline $\begin{array}{l}\text { Volatile fatty acid } \\
\text { number }\end{array}$ & -- & $0.05 \max$. & 0.0229 \\
\hline $\begin{array}{l}\text { Mechanical stability time } \\
\text { at } 55 \% \text { TSC }\end{array}$ & Sec. & $1000-1200$ & 1080 \\
\hline Specific gravity at $25^{\circ} \mathrm{C}$ & -- & 0.94 & 0.9448 \\
\hline Magnesium content & ppm & 40 max. & 36.75 \\
\hline $\begin{array}{l}\text { Viscosity at } 60 \% \mathrm{TSC} \text {, } \\
\text { spindle no. } 1 \text { at } 60 \mathrm{rpm}\end{array}$ & cps & -- & 59.50 \\
\hline $\begin{array}{l}\text { Coagulum content, } 80 \\
\text { mesh }\end{array}$ & ppm & -- & 20 \\
\hline
\end{tabular}

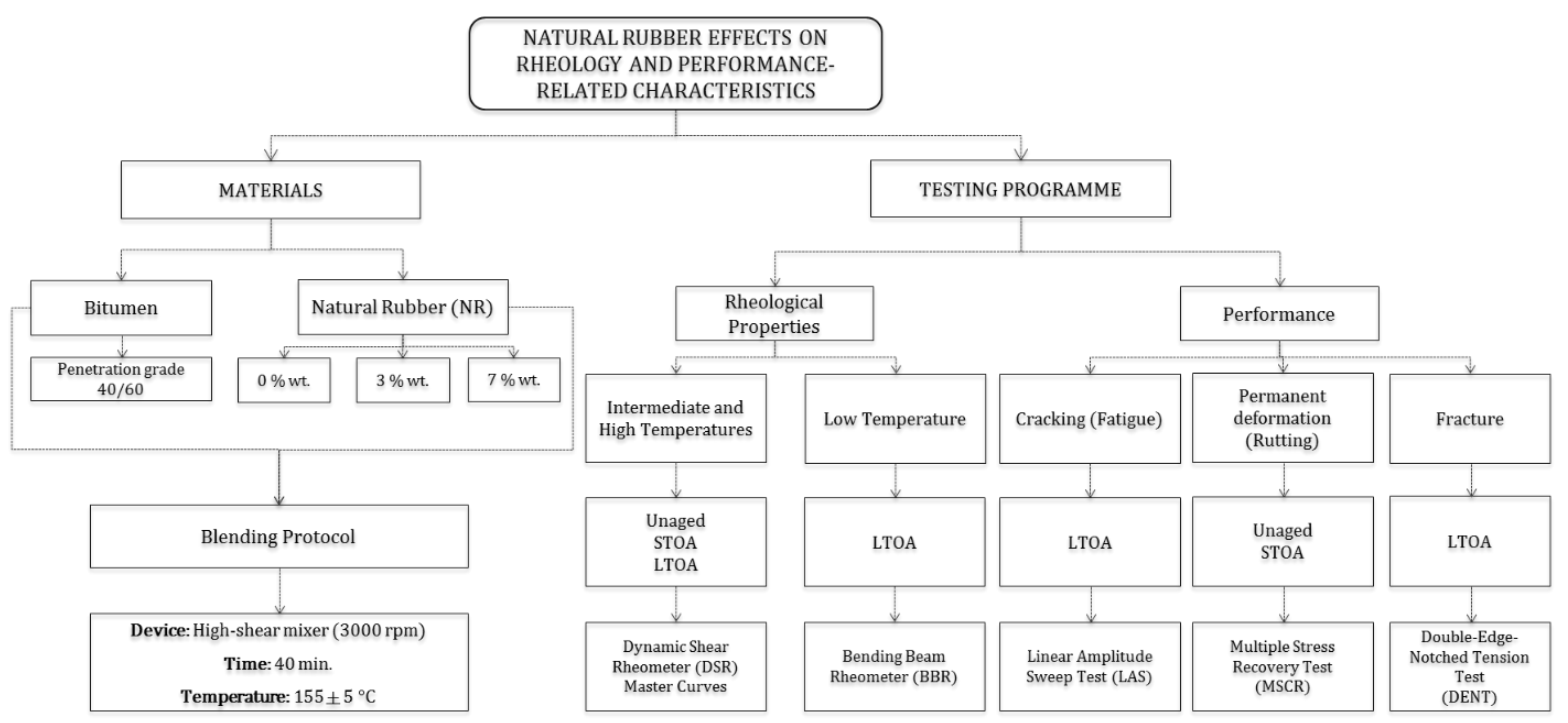

Figure 1. Testing programme for NRMB characterisation. Note: STOA refers to samples subjected to RTFO, LTOA refers to samples subjected to RTFO + PAV. 


\subsection{Blending Protocol}

A high-shear mixing approach was followed to guarantee sufficient material dispersion and interaction time between the base bitumen and NR. For this purpose, a high-shear mixer with double-head was used. The procedure for NRMB manufacture included the following steps: (1) The base bitumen (1500g) was preheated in an oven at $150^{\circ} \mathrm{C}$ for 120 minutes. Simultaneously, NR was weighed for mixing at the desired concentration. (2) The base bitumen was extracted from the oven and transferred to a hotplate with the high-shear mixer setup and the ability to keep the temperature at $150^{\circ} \mathrm{C}$. (3) The required amount of NR $(45 \mathrm{~g}$ and $105 \mathrm{~g}$ for $3 \%$ and $7 \%$ blend, respectively) were gradually added to the neat bitumen in order to minimize formation of lumps and air bubbles (due to the presence of water-base liquid) and thereby maximize blending efficiency. (4) The bitumen was manually stirred with a glass rod during NR addition until a fairly homogeneous blend was obtained with minimal formation of air bubbles. (5) Once the blend reached the target temperature on the hotplate $\left(150{ }^{\circ} \mathrm{C}\right)$, checked periodically with a hand thermometer, mechanical blending commenced from low speed (800 rpm) up to a maximum of 2,400 rpm (for 3\% NR content) and 4,200 rpm (for $7 \% \mathrm{NR}$ content).

\subsection{Linear Viscoelastic Rheological Characterisation}

Strain-controlled frequency sweep tests were conducted using a Bohlin Gemini® Dynamic Shear Rheometer (DSR) to determine the viscoelastic properties of the base bitumen and to assess the level of modification induced by NR. For this, parallel-plate geometry was used $(8 \mathrm{~mm}$ and $25 \mathrm{~mm})$ with $2 \mathrm{~mm}$ and $1 \mathrm{~mm}$ gap, respectively. The bitumen was heated up in the oven at $150{ }^{\circ} \mathrm{C}$ and then poured into the $8 \mathrm{~mm}$ and $25 \mathrm{~mm}$ moulds and samples were mounted in the DSR after the samples had cooled down and could be removed from the moulds. Low to intermediate temperatures $\left(5{ }^{\circ} \mathrm{C}\right.$ to $\left.35^{\circ} \mathrm{C}\right)$ were assessed with the $8 \mathrm{~mm}$ geometry, whereas high temperatures $\left(35^{\circ} \mathrm{C}\right.$ to $\left.75^{\circ} \mathrm{C}\right)$ used the $25 \mathrm{~mm}$ geometry. Frequencies from $0.1 \mathrm{~Hz}$ to $10 \mathrm{~Hz}$ were used with a strain level of $0.5 \%$ (within the Linear Viscoelastic Region (LVE), based on amplitude sweep tests). The timetemperature superposition principle (TTSP) was applied for shifting of the rheological data (i.e., $\left|G^{*}\right|$ and $\delta$ ) to produce smooth master curves. The shifting of the data was done using a $25{ }^{\circ} \mathrm{C}$ reference temperature with the application of the Williams-Landel-Ferry (WLF) model. In addition to the $\left|G^{*}\right|$ and $\delta$ master curves, a comparison of these parameters was made through Black Space Diagrams due to its simplicity as it does not require shifting of rheological data. These rheological parameters were used to study the relationship between stiffness and viscoelastic properties of the base bitumen and NRMBs [17].

\subsection{Performance-Related Tests}


A DSR was used to characterise the rheological and performance properties of the base bitumen and NRMB used to study the fatigue and permanent deformation performance-related characteristics of the materials. Fatigue cracking was assessed through the Linear Amplitude Sweep (LAS) test and permanent deformation (rutting) by means of the Multiple Stress Creep Recovery (MSCR) test. The fracture characteristics of the materials were determined using the Double-Edged Notched Tension (DENT) test. These are considered performance-related tests due to their ability to correlate material response to those of real pavement structures subjected to various loading regimes [18]. The detailed description of these tests is presented in subsequent sections.

\subsubsection{Linear Amplitude Sweep (LAS)}

The LAS test (AASHTO TP101) [19] was used to study the fatigue resistance of the base bitumen and NRMBs as a function of ageing and NR content. The test method is intended for accelerated damage and involves cyclic loading of bitumen samples that are subjected to increasing strain amplitudes. This leads to damage accumulation, which is used to assess fatigue performance in terms of the number of cycles required to failure (i.e., a decrease of the initial $\left|G^{*}\right|$ value at the peak shear stress, as per [19]). Aged bitumen samples of $8 \mathrm{~mm}$ diameter and $2 \mathrm{~mm}$ thickness are tested in a strain-controlled mode using the DSR parallel plate geometry. Two test stages are conducted: (1) The initial stage is non-destructive and involves assessing the undamaged rheological properties of the bitumen samples in terms of the complex modulus $\left(G^{*}\right)$ and phase angle $(\delta)$. This stage is done via a frequency sweep test (i.e., oscillatory loading from $0.2 \mathrm{~Hz}$ to $30 \mathrm{~Hz}$ at $0.1 \%$ strain amplitude). (2) Subsequently, the bitumen sample is subjected to a rest period of 10 s before the onset of the secondary stage. This secondary stage is destructive in nature through applying increasing strain amplitudes (from $1 \%$ to $30 \%$ strain) at a constant frequency of $10 \mathrm{~Hz}$ and is referred to as the continuous oscillatory strain sweep test. In brief, the test parameters include: (1) 100 loading cycles at $0.1 \%$ strain to obtain undamaged material response, and (2) 30 subsequent rounds of 100 cycles from $1 \%-30 \%$ strain, increasing linearly by $1 \%$, for a total of 3,100 cycles of loading [20].

Considering previous literature recommendations for minimizing the risk of delamination (i.e., poor bitumen/plate bonding), caution was taken to select the testing temperature [21]. To control delamination issues, the failure plane of the sample was checked at the end of the test to identify the typical torsional-fatigue failure of each specimen (i.e., circumferential crack) [22]. The temperature for LAS test was $15{ }^{\circ} \mathrm{C}$ and $25{ }^{\circ} \mathrm{C}$ for all 
materials, based on previous literature studying fatigue at intermediate temperatures [23]. The selection of two test temperatures was considered to assess the effects of this factor on the materials' fatigue response. In this study, two strain levels were considered to take into account both "strong" and "weak" pavement structures. For a "strong" layer with thickness higher than $100 \mathrm{~mm}$, a low strain $(\gamma=2.5 \%)$ was selected. Similarly, for a "weak" layer with thickness lower than $100 \mathrm{~mm}$, a higher strain $(\gamma=5.0 \%)$ was considered [24].

Viscoelastic continuum damage (VECD) mechanics, adopting Schapery's theory, was used to simulate damage growth and thus predict fatigue life as a function of strain (Equation 3). It is based on the simplified classic fatigue law (Equation 1) with $A$ and $B$ being obtained from the mathematical relationship between strain $(\gamma)$ and cycles to failure $\left(N_{f}\right)$ as shown in Equation 2,

$$
\begin{array}{cr}
N_{f}=A\left(\gamma_{\max }\right)^{B} & \text { Equation 1 } \\
A=\frac{f\left(D_{f}\right)^{k}}{k\left(\pi \frac{I_{D}}{\left|G^{*}\right|} C_{1} C_{2}\right)^{\alpha}}\left|G^{*}\right|^{-\alpha} & \text { Equation 2 } \\
B=-2 \alpha & \text { Equation 3 } \\
N_{f}=\frac{f\left(D_{f}\right)^{k}}{k\left(\pi \frac{I_{D}}{\left|G^{*}\right|} C_{1} C_{2}\right)^{\alpha}}\left|G^{*}\right|^{-\alpha}\left(\gamma_{\max }\right)^{-2 \alpha} &
\end{array}
$$

Where,

$k=1+\left(1-C_{2}\right) \alpha$,

$f$ is the loading frequency, $\mathrm{Hz}$,

$\left|G^{*}\right|$ is the undamaged complex shear modulus,

$\gamma_{\max }$ is the maximum expected binder strain for a given pavement structure in $\%$,

$D_{f}$ is the damage accumulation at failure, defined as the $D(t)$ corresponding to the reduction in initial $\left|G^{*}\right|$ at the peak shear stress.

\subsubsection{Double-Edged Notched Tension (DENT)}

The fracture characteristics in the ductile state of bitumen/NRMBs were studied following the Canadian Standard (Test Method LS-299) [25]. The essential work of fracture required to generate new surfaces was studied through the DENT test, which was used to determine the ductile failure resistance under horizontal tensile load application, at a specified temperature $\left(15^{\circ} \mathrm{C}\right)$. Initially, as per standard guidelines, a $15{ }^{\circ} \mathrm{C}$ test temperature was considered, but at this condition the samples exhibited a premature brittle-failure (i.e., sample breakage). For this reason, the selection of a higher testing temperature of $25{ }^{\circ} \mathrm{C}$ was required in order to 
facilitate a more ductile material response. The fracture properties studied included: (1) The essential work of fracture $\left(W_{e}\right)$, (2) plastic work of fracture $\left(W_{p}\right)$, and (3) the approximated critical crack-tip opening displacement $(C T O D)$. These properties were calculated to study the resistance of the bitumen/NRMBs to ductile fracture. The DENT test was conducted after conditioning of the samples in a water bath (i.e., the specimens were submerged $25 \mathrm{~mm}$ below water surface) at $25{ }^{\circ} \mathrm{C}$ for 180 minutes. The deformation load was applied at a controlled rate of $50 \mathrm{~mm} / \mathrm{min}$ and it stopped when all the samples reached the ductile failure. During testing, data of the elongation length (in $\mathrm{mm}$ ), and force (in Newtons) was recorded and subsequently analysed to determine the fracture parameters (i.e., $W_{e}, W_{p}$ and $\left.C T O D\right)$ ).

The significance of the measured properties for the comparison of the materials' fracture performance relate to: (1) the total work of fracture $\left(W_{t}\right)$, which refers to the area under the load versus load-line displacement curve, $\mathrm{kJ}$ (Equation 4); (2) the specific total work of fracture $\left(w_{t}\right)$, related to each replicate sample tested, $\mathrm{kJ} / \mathrm{m}^{2}$ (Equation 5); (3) the specific essential work of fracture $\left(w_{e}\right)$, the energy required to fracture or break the sample without plastic deformation away from the fracture zone, $\mathrm{kJ} / \mathrm{m}^{2} ;(4)$ the specific plastic work of fracture $\left(w_{p}\right)$, the non-essential work dissipated during the deformation of a volume of bitumen around the fracture zone, $\mathrm{MJ} / \mathrm{m}^{3}$; (5) the geometric constant of the plastic zone $(\beta)$, and (6) the critical tip opening displacement (CTOD), mm (Equation 6 and Equation 7).

$$
W_{t}=\int_{0}^{t_{f}} P \times d
$$

Equation 4

Where,

$P$ is the load in Newtons,

$d$ is the displacement in the test in $\mathrm{m}$,

$t_{f}$ is the time when the maximum stroke is reached or ductile failure, whichever is attained first.

$$
w_{t}=\frac{\left(\text { average } W_{t}\right)}{(B \times l)}
$$

Where,

$B$ is the sample thickness in $\mathrm{m}$, and

$l$ is the ligament length (the space between the notches) in $\mathrm{m}$.

$$
\operatorname{COTD}=\frac{w_{e}}{\sigma_{n}}
$$

Equation 6

Where,

$\sigma_{n}$ is the net section stress of specimen in $\mathrm{N} / \mathrm{m}^{2}$, calculated using 


$$
\sigma_{n}=\frac{P_{p e a k}}{(B \times l)}
$$

Where,

$P_{\text {peak }}$ is the average peak load of the specimen tested with the smallest ligament length (i.e., the average maximum load for the $5 \mathrm{~mm}$ ligament specimens).

Determination of $w_{e}$ and $\beta w_{p}$ was done either graphically by plotting $w_{t}$ for the three ligament lengths or mathematically using the least squares fitting method. $w_{e}$ refers to the specific essential work of fracture (i.e., $\mathrm{w}_{\mathrm{t}}$ value when $1=0.0$ ) and $\beta w_{p}$ is the slope of the best fit straight line (for $w_{t}=w_{e}+\beta w_{p} l$ ).

\subsubsection{Multiple Stress Creep Recovery (MSCR)}

The MSCR test was used to determine the permanent deformation susceptibility of the base bitumen and NRMBs. This test was conducted on unaged and RTFO-aged materials to study their elastic recovery properties. A DSR parallel-plate geometry with spindle diameter of $25 \mathrm{~mm}$ and $1 \mathrm{~mm}$ testing gap was used to undertake the test, using a Bohlin $\mathrm{CVO} \circledast$ equipment. Test temperature of $60^{\circ} \mathrm{C}$ was selected based upon typical ranges reported in literature for pavement surface temperature in Thailand $\left(65-68{ }^{\circ} \mathrm{C}[26]\right.$; and $53-59{ }^{\circ} \mathrm{C}$ [27]). The test followed the AASHTO TP 70 Standard method [28]. In brief, the sample was loaded for 20 cycles of creeprecovery at $0.1 \mathrm{kPa}$ stress levels and 10 cycles for the $3.2 \mathrm{kPa}$ stress condition. First, a 1 second creep load is applied and subsequently released for 9 seconds. Data was recorded by the DSR equipment and subsequently analysed in terms of the \% recovery $(R$-Value $)$, the non-recoverable creep compliance $\left(J_{n r}\right)$, and the stress sensitivity parameter $\left(J_{n r-d i f f}\right)$. Equations as per standard were used to calculate the parameters for both stress conditions $(0.1 \mathrm{kPa}$ and $3.2 \mathrm{kPa})$. The $R$-value refers to the ability of bitumen to recover (i.e., dissipate stresses) after repeated loading and higher values reflect better material response in terms of permanent deformation. The $J_{n r}$ is an indicator of permanent deformation resistance that for higher values indicates a higher susceptibility to rutting distress of a given bitumen. The $J_{n r-d i f f}$ is used to distinguish the stress sensitivity of the bitumen due to the change of low stress $(0.1 \mathrm{kPa})$ to high stress $(3.2 \mathrm{kPa})$ conditions. Higher values of this parameter indicate higher sensitivity to the change in the loading stress to which the bitumen is subjected to under specific temperature conditions.

\subsection{Low-temperature Rheological Characterisation}

The low-temperature rheological properties for the bitumen/NRMBs were studied by means of the Bending Beam Rheometer (BBR) in accordance with the AASHTO T313-12 Standard [29]. In brief, the test method 
involved the application of a $980 \mathrm{mN}$ load to the beam specimen during 60 seconds of loading using the threeproperties (m-values) were recorded and later analysed for assessing the temperature/concentration effects and determination of critical low-temperature values $\left(T_{c}(S)\right.$ and $\left.T_{c}(m)\right)$ and the differential of these values, Delta Tc $\left(\Delta T_{C}\right)$. The measured stiffness was calculated using the loading, deflection values and geometrical features of the beams manufactured by using the beam theory. The estimated stiffness was calculated from a mathematical fitting of the data. The m-value refers to the slope of the relationship between the logarithmic of measured stiffness and is obtained at the logarithm of time for the total of 240 seconds of loading. Test temperatures included for the low-temperature characterisation included $-18{ }^{\circ} \mathrm{C}$ and $-24{ }^{\circ} \mathrm{C}$.

$\Delta T c$ values were calculated using Equation 8. This parameter is a measure of the closeness of the critical low temperatures measured from the Stiffness and m-value with respect to their influence on the low temperature. Previous research has suggested this parameter is valid for more accurate prediction of field performance of bitumen (fatigue cracking response) as a result of its relation to bitumen ductility [30]. This research proposed two limits for $\Delta T c$ that refer to a cracking warning level and a limiting value of $-2.5{ }^{\circ} \mathrm{C}$ and $-5.0^{\circ} \mathrm{C}$. These criteria were incorporated for the discussion of results. The critical low-temperature values $\left(T_{c}(S)\right.$ and $\left.T_{c}(m)\right)$ were determined as per standard. From these values, the higher temperature is selected as the critical one for a given material [31].

$$
\Delta T c=T c(\text { Stiffness })-T c(m-\text { value })
$$

Equation 8

Where: $T c$ is the critical temperature for each of the BBR parameters $(S$, m-value $)$.

\subsection{Ageing Protocols}

To simulate ageing occurring during manufacturing and laying of bituminous mixtures, Short-Term Oven Ageing (STOA) and Long-Term Oven Ageing (LTOA) protocols were conducted on the base bitumen and NRMBs manufactured through the blending approach previously described. The STOA was carried out with the Rolling Thin Film Oven (RTFO) test [32] and LTOA with the Pressure Ageing Vessel (PAV) [33].

The effects of NR on NRMBs are analysed in terms of: (i) rheological characteristics at low-intermediate-high temperatures, and (ii) performance-related responses (fatigue performance, permanent deformation resistance and fracture properties). The effects of short- and long-term oven ageing on the rheology and performancerelated characteristics of NRMBs are also quantified. 


\section{Rheological Changes Induced by NR}

\subsection{Intermediate-High Temperature Effects (Master Curves)}

The effects of NR in terms of the rheological changes induced to the base bitumen at the three NR concentrations were assessed in terms of complex modulus $\left(G^{*}\right)$, phase angle $(\delta)$ master curves and the Black Diagrams. For the sake of brevity, only the results of the unaged materials are shown taking into consideration that similar observations were attained for the short-term (RTFO) and long-term (RTFO + PAV) ageing conditions in terms of $G^{*}$ and $\delta$ master curves and Black Space diagrams. The rheological results in Figure 2 show that the effects of NR on the rheological parameters $G^{*}$ and $\delta$ are more pronounced at higher temperatures and lower loading frequencies as demonstrated in Figure 2a, and Figure $2 \mathrm{~b}$. These results indicate that NR produces NRMBs with an increased elastic response (i.e., lower phase angles) and increased stiffness (i.e., higher complex modulus) in comparison to the control bitumen, with more significant modification level reached for the maximum NR concentration (7\% NRMB). At lower testing temperatures (i.e., higher loading frequencies) the complex modulus master curves show a decrease in the $G^{*}$ values for increasing NR dosages as compared to those of the control bitumen. While the change of $\delta$ with temperature and frequency is generally consistent with that of the $G^{*}$ master curves, the differences between the three binders are less evident at lower testing temperatures (higher loading frequencies).

The rheological data shown in the $\mathrm{G}^{*}$ and $\delta$ master curves is also plotted in the form of Black Space diagrams (Figure 2c) and used as an indicator of rheological changes induced by NR without the need to shift the data based on the time-temperature-superposition-principle (TTSP) [17]. The Black Space diagrams indicated a shift of the curves towards a more elastic behaviour (i.e., lower $\delta$ for both NRMBs) as the NR dosage increased, particularly for the higher $7 \%$ NR content. For the 3\% NR NRMB the level of modification is restricted to the high temperature (i.e., low frequency) domain with the rheological behaviour at low temperatures (i.e., high frequencies) being similar to that of the control bitumen. The Black diagrams also indicated that increased NR content produced a reduction in $G^{*}$ that substantiates the increased ductile response induced by NR on the binder rheology (discussed further for the low temperature BBR rheological results). Although not shown in Figure 2 for the sake of brevity, the effects of NR modification for the short- and long-term aged binders were consistent with those discussed for the unaged binders with the effect of ageing simply indicating an overall increase in $G^{*}$ and a reduction of $\delta$ values for all the binders as ageing increases. Overall, the comparison of the rheological parameters presented in Figure 2 substantiated the ability of NR to produce a more elastic response for the NRMBs as compared to that of the control bitumen. These results suggest an improvement of the 
permanent deformation resistance for increased NR content NRMBs due to their increased elastic response at high temperatures.

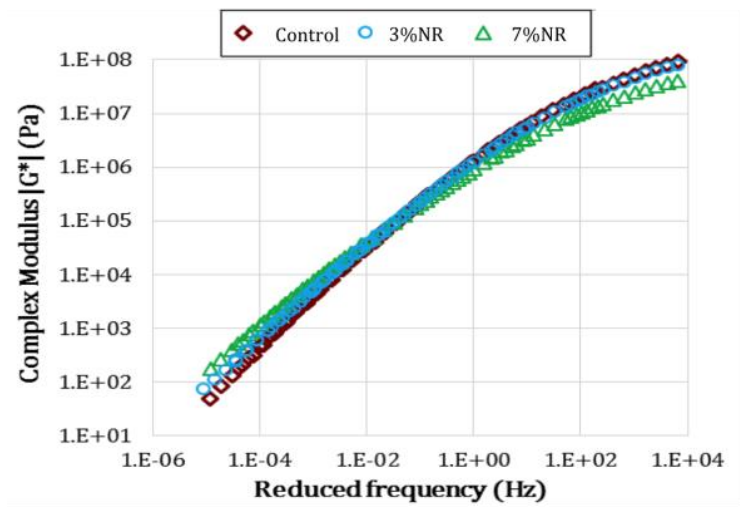

(a)

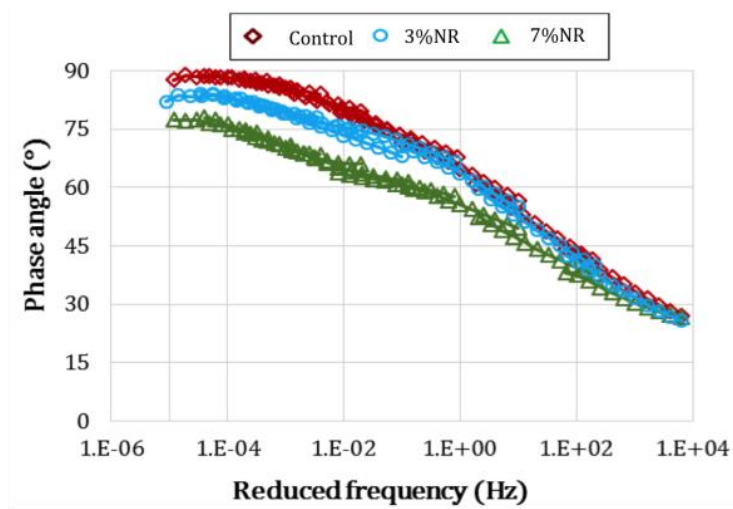

(b)

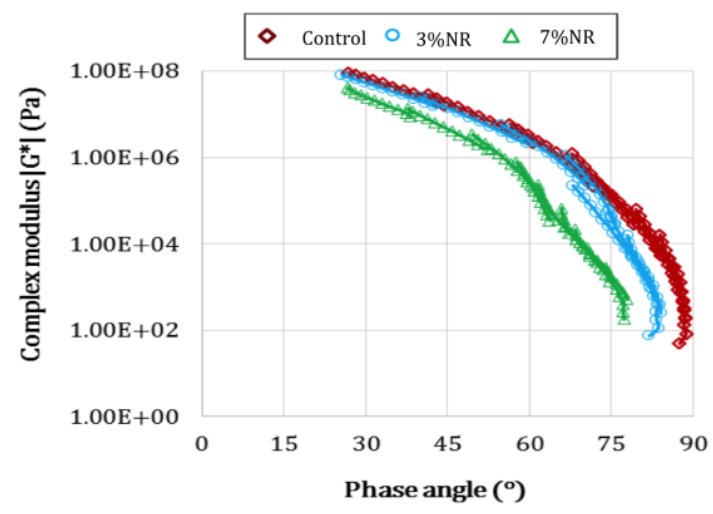

(c)

Figure 2. Comparison of the effects of NR on the rheological characteristics in terms of: (a) $G^{*}$ master curves, (b) $\delta$ master curves, and (c) Black-Space diagrams for unaged materials.

\subsection{Low-Temperature Effects and Thermal Cracking Susceptibility (BBR)}

The $S$ - and $m$-value comparisons for the two testing temperatures considered in this study are shown in Table 2. From these values, the effect of NR on the low-temperature rheological behaviour showed a reduction of $S$ values (creep stiffness) as NR content increased from the control binder to $3 \%$ and $7 \%$ NR. However, the effect of NR on the relaxation properties (m-values) suggested a slower relaxation of the thermal stresses of the NRMBs considered in this study in contrast to that of the control bitumen. This means that high NR contents could induce brittle material response as a result of a reduced ability of these binders to stretch (i.e., lower ductility or loss in relaxation). However, the use of $m$-value does not represent a final indication of poor or good thermal cracking performance, as this parameter is associated with thermal stresses build up and the time required/available by the material to release these, which ultimately depends on the location and climate [34]. In 
consequence, the fact that the increase in NR content induced lower m-values does not imply that these NRMBs would have detrimental performance as this will depend on the weather conditions to which the pavement will be subjected to and it also depends on the $S$ values at low temperature, which were found to be lowered by the increase in NR content. As such, if one considers NR application in warmer climates, both $S$ and $m$-values do not represent a major risk as these locations are not subject to major thermal stresses with lowest temperatures being typically around $15^{\circ} \mathrm{C}$ at which block cracking or thermal cracking are not distresses of concern. For applications of NR in low-temperature regions, both BBR parameters and $\Delta T c$ need to be considered to find a balanced performance that satisfies the specifications imposed by the location/climate and the intrinsic material low-temperature response.

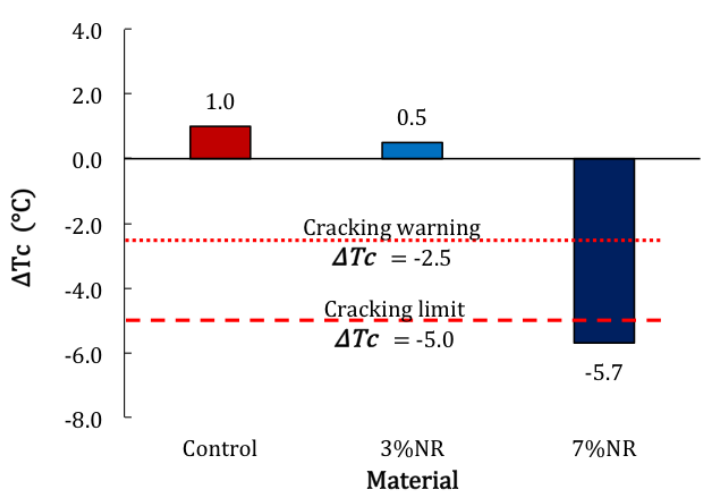

From

Figure 3 and Table 2 it is observed that the base bitumen and 3\% NRMB satisfied both cracking limits for lowtemperature for the $\Delta T c$ criterion, whereas the increase of NR to $7 \%$ did not comply and it is therefore expected to have high susceptibility to thermal cracking. This is probably a consequence of the effects of high-polymeric modification of bitumen with NR, which could lead to higher susceptibility of NRMBs to thermal cracking at high concentrations, as previously reported by $[35,36]$. In brief, from the rheological characterisation at lowtemperatures it was found that: $(i)$ NR induced positive effects on the NRMBs in terms of a reduction of the creep stiffness $(S)$ at $-18{ }^{\circ} \mathrm{C}$ and $-24{ }^{\circ} \mathrm{C}$, which is indicative of lower thermal stresses induced by both $\mathrm{NR}$ contents considered; (ii) Conversely, the relaxation properties ( $m$-values) were negatively affected by increased NR content, which suggests a lower ability of the NRMBs to relax stresses (i.e., lower ductile response) in contrast to the control bitumen and; (iii) in terms of thermal cracking resistance, it was found that modification of control bitumen with NR content up to $3 \%$ would have satisfactory performance on the basis of the $\Delta T c$ failure criteria. 
Table 2. Low-temperature properties (S, m-value) and critical temperatures and the corresponding differential temperature $\Delta T c$.

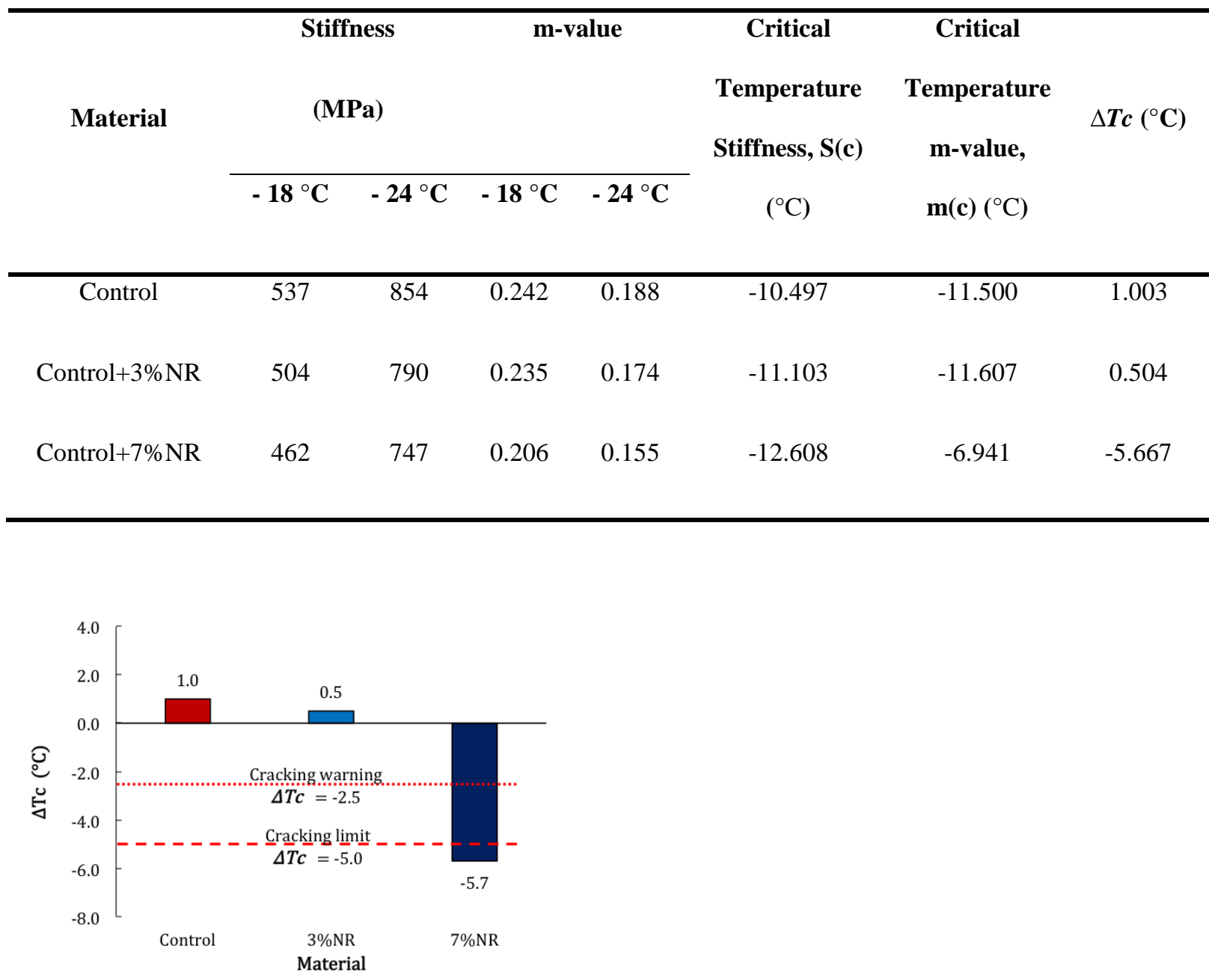

Figure 3. Comparison of the thermal cracking susceptibility for control bitumen and NRMB in terms of $\Delta T c$ values.

\section{Performance-Related Effects of NR}

\subsection{Effects of NR on Fatigue Performance}

The characteristic VECD coefficients for the base bitumen (control) and NRMBs are presented in Table 3. The trends observed in the VECD coefficients indicate both the effects of temperature and NR content, which induced differences in the damage response that was captured via the $C_{0}, C_{1}$ and $C_{2}$ coefficients. The results show an increase of $C_{l}$ was induced by the increase in NR content, whereas $C_{2}$ decreased for increased NR content. These differences substantiate the fact that $7 \%$ NRMB presents a higher reduction in initial $\left|G^{*}\right|$ at low damage intensity levels, whereas the reduction is less prominent for higher levels of damage. Furthermore, this indicates that both NR contents induced positive effects on the damage resistance (captured by lower decrease in the initial $\left|G^{*}\right|$ in comparison to the base bitumen) that turn into higher fatigue cracking resistance as further 
discussed in this section. Overall, the assessment of the VECD damage coefficients indicated that the largest $C_{0}, C_{l}$ and smallest $C_{2}$ values relate to the NRMB with $7 \% \mathrm{NR}$. The temperature effects of $10^{\circ} \mathrm{C}$ difference on the fatigue performance were also captured as reflected by the changes in the VECD coefficients, the damage intensity curves and the fatigue life curves. The results show that the higher $25{ }^{\circ} \mathrm{C}$ test and analysis produced significantly lower $C_{0}$ and $C_{1}$ values whereas $C_{2}$ remained almost unaltered. The damage intensity curves substantiated significant reduction in the stiffness of the materials as a result of the temperature increase and the fatigue life reflected this effect in higher $N f$ for the higher testing temperature. Overall, it was found that the addition of NR produced NRMBs with higher damage resistance in contrast to the base bitumen.

Table 3. VECD coefficients for control and NRMB at $15{ }^{\circ} \mathrm{C}$ and $25^{\circ} \mathrm{C}$.

\begin{tabular}{|c|c|c|c|c|c|c|}
\hline \multirow{2}{*}{ Material } & \multicolumn{3}{|c|}{$15^{\circ} \mathrm{C}$} & \multicolumn{3}{|c|}{$25^{\circ} \mathrm{C}$} \\
\hline & $\mathrm{C}_{0}$ (MPa) & $\mathrm{C}_{1}(\mathrm{MPa})$ & $\mathrm{C}_{2}$ & $\mathrm{C}_{0}$ (MPa) & $\mathrm{C}_{1}$ (MPa) & $\mathrm{C}_{2}$ \\
\hline Control & 44.51 & 0.092 & 0.434 & 13.2 & 0.084 & 0.424 \\
\hline Control $+3 \%$ NR & 44.06 & 0.117 & 0.381 & 12.93 & 0.104 & 0.383 \\
\hline Control $+7 \%$ NR & 46.52 & 0.149 & 0.344 & 16.81 & 0.179 & 0.299 \\
\hline
\end{tabular}

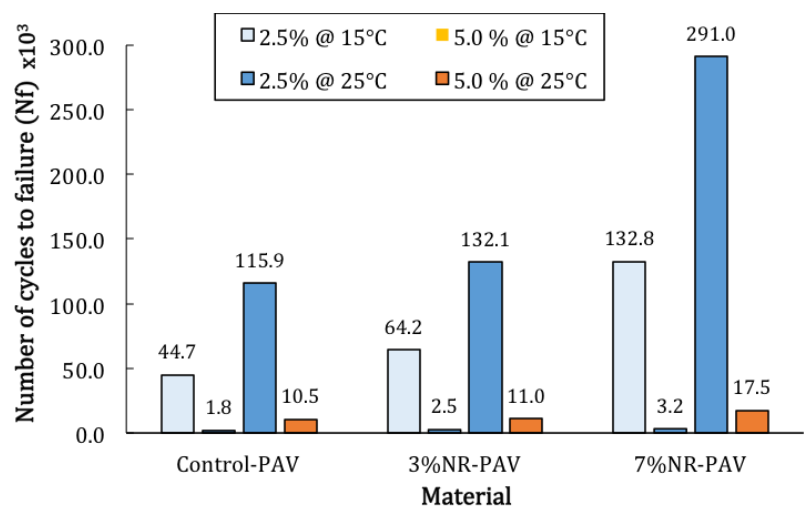

Figure 4. Comparison of fatigue lives for PAV-aged materials at $2.5 \%$ and $5 \%$ strain at $15{ }^{\circ} \mathrm{C}$ and $25{ }^{\circ} \mathrm{C}$.

A comparison of the fatigue lives (number of cycles to reach failure, $N_{f}$ ) are shown in Figure 4. As observed previously, temperature and NR content effects were identified. For both temperatures, $N_{f}$ increased as a function of the NR content, which was consistent for both the low and high strains considered $(\gamma=2.5 \%$ and $\gamma=$ 5.0\%). At $15^{\circ} \mathrm{C}$ testing temperature and $2.5 \%$ strain, a $44 \%$ increase in fatigue life was found for $3 \% \mathrm{NR}$ and a $197 \%$ increase for $7 \% \mathrm{NR}$ in contrast to that of control bitumen. At $15{ }^{\circ} \mathrm{C}$ and $5 \%$ strain, this increase was less prominent ( $36 \%$ for $3 \% \mathrm{NR}$ and $76 \%$ for $7 \% \mathrm{NR}$ ). The effects of increasing the test temperature by $10^{\circ} \mathrm{C}$ also produced differences in the fatigue lives, which were reflected by higher $N_{f}$ values for the $25^{\circ} \mathrm{C}$ testing temperature for all materials and strains considered. From the macroscopic perspective (i.e., visual inspection of 
the samples after testing), the fatigue of all the materials exhibited a failure plane that followed a factory-roof morphology and a circumferential torsional failure (i.e., growing from the inside to the outside of the bitumen/NRMBs specimens), which is consistent with previous findings by [22] and substantiates an adequate bitumen/plate bonding during testing.

\subsection{Effects of NR on Permanent Deformation Resistance}

The effects of NR on permanent deformation resistance is presented and discussed in this section in terms of the evolution of accumulated strain over time, the effects of ageing, and the comparison of rutting parameters (nonrecoverable creep compliance $J_{n r}$, percent recovery $R$-value, stress sensitivity parameter $J_{n r-d i f f}$ ).

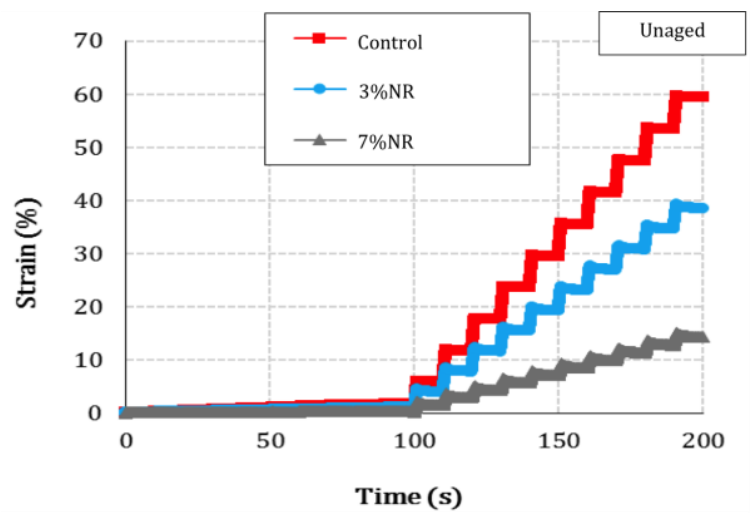

(a)

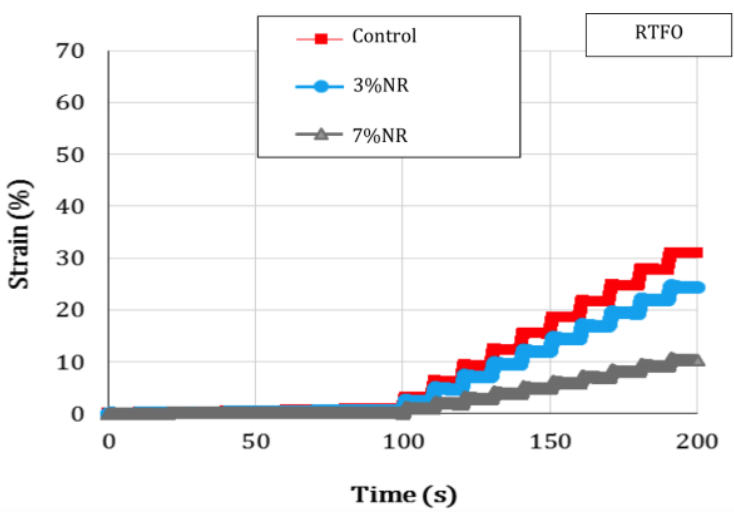

(b)

Figure 5. Strain versus time for (a) unaged bitumen, and (b) RTFO aged bitumen, at $60{ }^{\circ} \mathrm{C}$.

The strain and accumulated strain versus time presented in Figure 5 and Figure 6, respectively, show a positive effect of NR on increased resistance to permanent deformation in contrast to the base bitumen. In Figure 5, the initial 100 seconds refer to the $0.1 \mathrm{kPa}$ stress condition and the subsequent steps of cumulative strain are due to the impact of a much higher stress regime $(3.2 \mathrm{kPa})$, which is easily observed and captures the effect of NR modification of the base bitumen. The higher NR contents induced a reduction in the accumulated strain for both NRMBs with 3\% NR and 7\% NR, which was observed for both unaged and STOA conditions and for both stress levels considered $(0.1 \mathrm{kPa}$ and $3.2 \mathrm{kPa})$. This reduction in accumulated strain highlights a positive influence exerted by NR on bitumen modification in terms of reduced permanent deformation susceptibility of the NRMBs in comparison to that of control bitumen (Figure 6). 


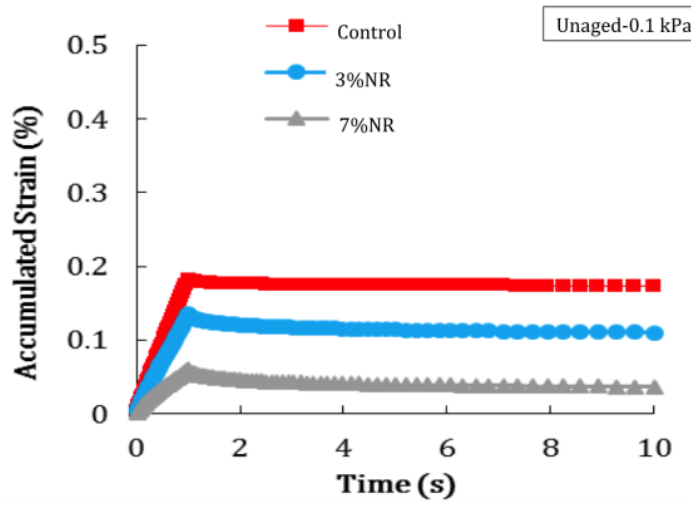

(a)

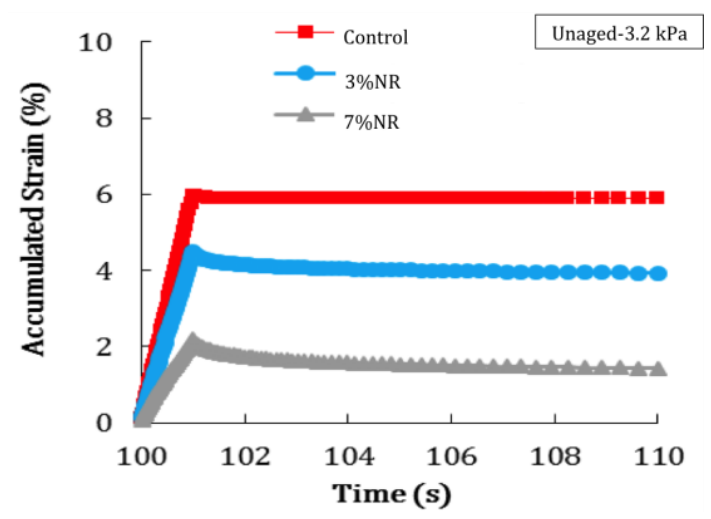

(c)

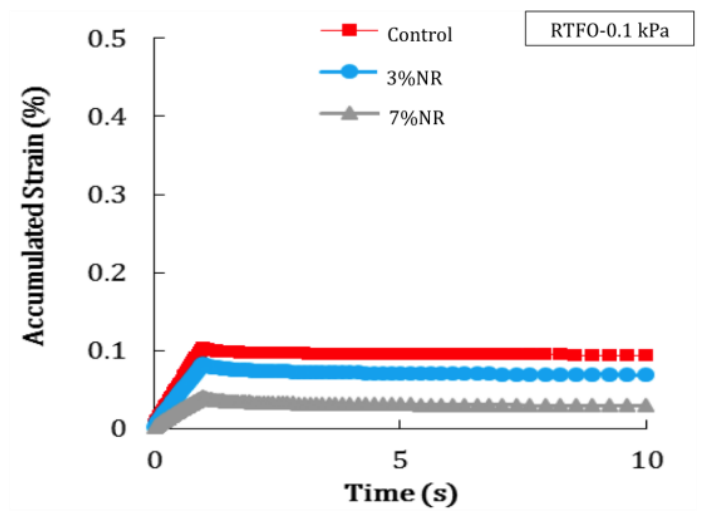

(b)

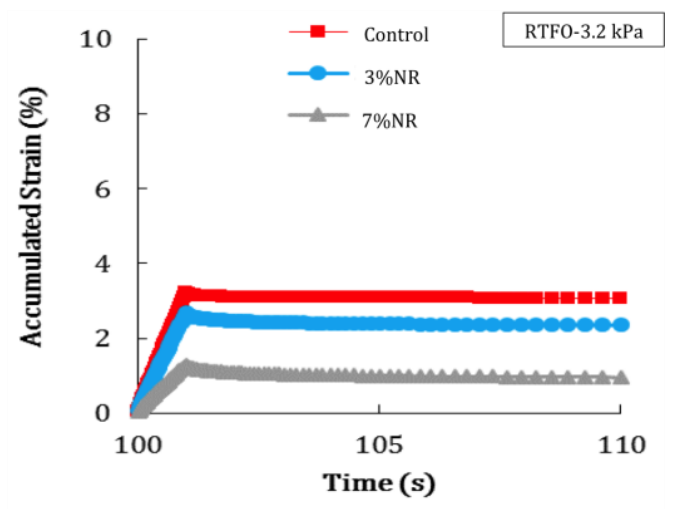

(d)

Figure 6. Effects of stress on the accumulated strain for unaged, and RTFO-aged bitumen, at $60{ }^{\circ} \mathrm{C}$. (a) Unaged at $0.1 \mathrm{kPa}$, (b) RTFO at $0.1 \mathrm{kPa}$, (c) Unaged at $3.2 \mathrm{kPa}$, and (d) RTFO at $3.2 \mathrm{kPa}$.

The effects of NR on the resistance to permanent deformation, assessed in terms of the average percentage recovery $(R$-value $)$ and non-recoverable creep compliance $\left(J_{n r}\right)$, indicated that increasing NR content enhanced this material response as compared to that of the base bitumen. Consistently for both unaged and RTFO-aged materials and at both stress levels, it was observed that $J_{n r}$ decreased and the $R$-values increased as the NR content increased. Figure 7 show the effects of STOA ageing, NR content and stress level on the nonrecoverable creep compliance $\left(J_{n r}\right)$. The change from unaged to STOA produced stiffer materials as captured by the lower $J_{n r}$ values for both control bitumen and NRMBs at 3\%NR and $7 \%$ NR content. The increase in stress level from $0.1 \mathrm{kPa}$ to $3.2 \mathrm{kPa}$ increased the value of $J_{n r}$ by approximately $10 \%$. Furthermore, the effect of increased NR content showed a clear trend of reduction in the $J_{n r}$ values for both stress levels and ageing conditions, which substantiates the positive influence of NR on this material response.

These parameters provide evidence of the positive effects of NR on the permanent deformation resistance of the modified control bitumen. Similarly, the effects of ageing were also demonstrated based on the $J_{n r}$ and $R$-values shown in Figure 8. Similar to the effect seen for unmodified binders, subjecting the NRMBs to STOA improves 
the rutting resistance of the modified binders meaning that positive observations in terms of permanent deformation resistance held true for both NR content and ageing condition.

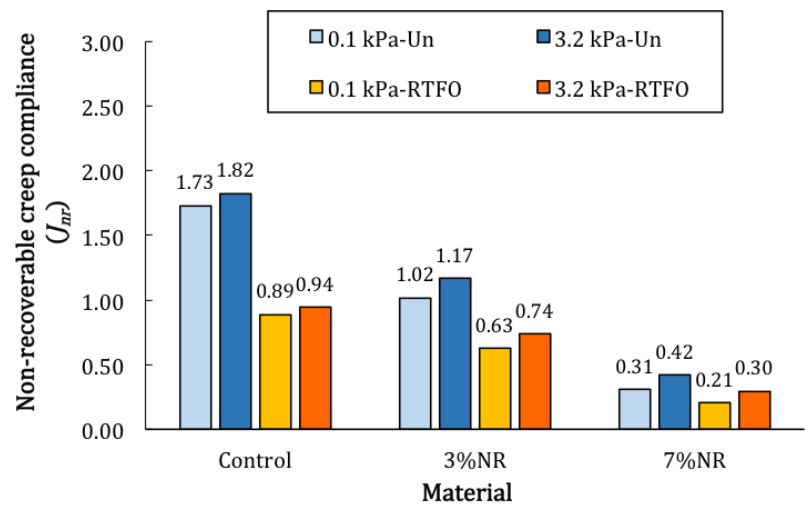

Figure 7. Comparison of the effect of NR and ageing on the permanent deformation, presented in terms of nonrecoverable creep compliance $\left(J_{n r}\right)$ for unaged materials, and RTFO aged materials.

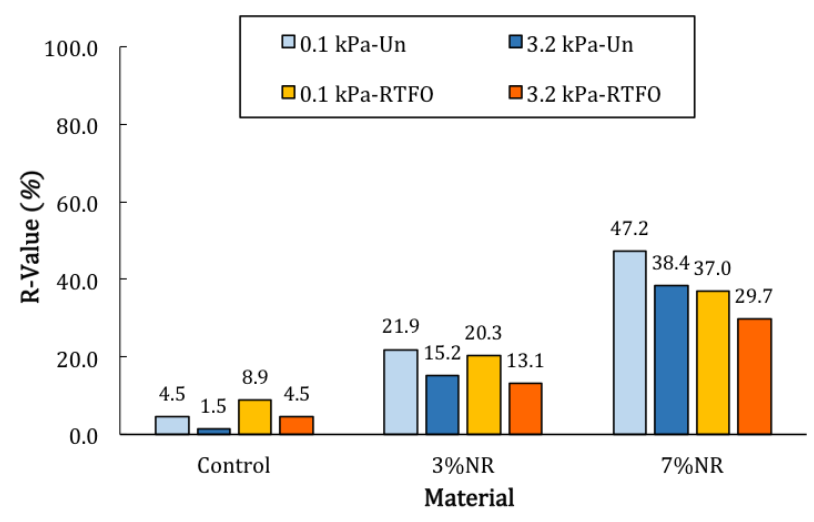

Figure 8. Comparison of the effect of NR and ageing on the permanent deformation, presented in terms of average percentage recovery ( $R$-value) for unaged materials, and RTFO aged materials.

The $J_{n r}$ results are in agreement with those observed for the R-values with higher R-values indicating a higher resistance to permanent deformation. As such, the combined effects of ageing, stress level and NR content are presented in Figure 8, where it becomes clear that ageing and NR content increased the permanent deformation resistance of the binders. Furthermore, as it would be expected for bituminous materials, the increase of stress level induced a substantial decrease of the R-values, indicating the stress sensitivity of the materials with increased NR content. The reduction in the percent recovery $(\% \mathrm{R})$ is explained by the possible damaging of the NR crosslink structure (i.e., polymer network stability) induced by this short-terms ageing protocol, which inevitably affects the permanent deformation response of the NRMBs at both concentrations studied. Under this oxidative condition, the hardened bitumen phase is responsible for the most part of the rheological response. 
Previous research found similar results of dropping recovery values when polymer-modified bitumen blends were subjected to artificial ageing cycles in both RTFO and PAV $[35,36]$. Furthermore, the $J_{n r-d i f f}$ values shown in Figure 9 substantiate the increase in the stress sensitivity induced by increased NR content for the bitumens considered. However, this is a common effect of high polymer modification of bitumen, which has been reported for the permanent deformation performance of polymer modified asphalt (PMA) mixtures [37, 38]. From these results, however, it is surprising that short-term ageing of the 7\% NRMB did have a reduction of the stress sensitivity, which could result from possible errors in rheological data captured by DSR due to the high stiffness gain induced by the high-NR content in contrast to $3 \%$ NR or the base bitumen, or it might be related to variability between replicate materials during production of the DSR samples. Therefore, from $J_{n r-d i f f}$, it might be deduced that higher NR contents led to detrimental effects on the stress sensitivity for both ageing conditions, which needs to be considered for optimum dosage selection in conjunction with other performance-related characterisations to attain a balanced performance for a given NR content. However, based on standard recommendations [39], all the materials fulfilled the criteria as they were all below $75 \%$, which suggests satisfactory stress sensitivity for both NR contents.

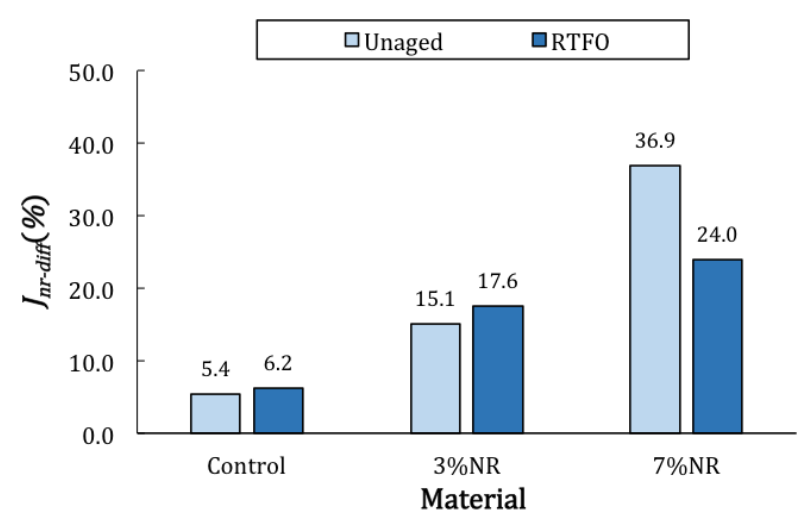

Figure 9. Stress sensitivity for unaged and RTFO-aged materials.

\subsection{Influence of $\mathrm{NR}$ on the fracture characteristics}

The specific total work of fracture $(W t)$, essential work of failure $(W e)$, plastic work of failure $\left(\beta w_{p}\right)$, and critical crack opening displacement $(C T O D)$ are presented in this section to discuss the effects of NR on the fracture properties of the modified binders. Prior to the fracture parameters, the plane-stress/plane-strain mixed mode of testing was verified through the correlation between net section stress and ligament length, which indicated a decrease in the net section stress as the ligament length increased. The $W t$ values for the base bitumen and NRMB at 3\% and $7 \%$ are shown in Figure 10 where a higher slope can be observed for $7 \%$ NR content in 
contrast to the base bitumen and 3\% NR. These results indicate an improved yielding capacity and increase in the fracture energy for NRMB with $7 \%$ NR content, whereas the $3 \%$ NR content did not produce the same extent of influence on the fracture energy and therefore its yielding capacity is reduced [38]. As observed in

Figure 10, the essential work of fracture for $3 \%$ NR content exceeded that of the base bitumen, whereas $7 \%$ NR content provided the lowest We values. This indicates that the $3 \% \mathrm{NR}$ content enhanced the resistance to fracture due to a higher ductile strain tolerance in contrast to those of the base bitumen and $7 \%$ NR. This finding is consistent with previous research $[39,40]$. The former study showed a positive correlation between higher $W t$ values and $\beta w_{p}$ with enhanced fatigue cracking of real pavement sections due to enhanced ductile strain tolerance. The latter study proved that inclusion of RAP to polymer modified bitumen led to unsatisfactory fracture properties, which included decreased $\mathrm{Wt}$ and $\beta w_{p}$ values.

The plastic work of failure ( $\beta w_{p}$ values related to the slopes of the curves) is shown in Figure 10a and this parameter was used as an indicator of the fatigue cracking resistance of the base bitumen and NRMBs based on recent literature [42]. It can be observed that for the $7 \% \mathrm{NR}(0.7726)$, the $W_{t}$ increases at a higher rate in contrast to that of the base bitumen (0.5112) and 3\% NR (0.2765), respectively, which would suggest $7 \%$ as the most adequate NR concentration. However, other fracture properties are also required for confirming this observation, thus $C T O D$ and $W_{e}$ were also determined. The $C T O D$ values are in agreement with those of $W_{e}$ (Figure 10b), which substantiates the fact that NR contents above $3 \%$ might lead to deleterious effects on the fracture resistance for the material combinations studied in this paper. This could be the result of NR concentrations reaching a maximum level of yielding capacity and strain tolerance that is below the $7 \%$ studied in this paper. This might be due to the physicochemical reaction of higher NR content with the base bitumen due to the higher concentration of polymeric chains in the bitumen matrix that are able to alter the ductile response under high strain concentrations at the testing temperatures considered. Similarly, the data presented in Table 4 is consistent with the previous discussion of the fracture parameters in terms of the failure deformation and peak load. These results show that a NR content of $3 \%$ leads to improved fracture resistance as a consequence of the lower peak loads and increased deformation. The $3 \% \mathrm{NR}$ content therefore induced better fracture properties for the materials studied, whereas $7 \%$ NR exhibited detrimental effects on the fracture of NRMBs.

Furthermore, the results observed for the maximum concentration of NR in the NRMBs might be associated by the detrimental side effects produced by the artificial ageing regimes (i.e., RTFO and PAV) that are required prior testing for DENT. More precisely, as discussed before, the polymer network or cross-link of the NR 
molecules seems to be disintegrated by the short- and long-term ageing, which results in stress concentration in

the bitumen matrix. Previous research on fracture response of SBS-modified bitumen through DENT testing found that high polymer concentrations (i.e. higher than $2 \%$ ) tend to have poorer fracture performance in comparison to reasonably low contents of modifiers. In fact, the use of WMA additives such as Fischer-Tropsch (FT), chemical surfactants (CS) and water-based (WB) have the ability to modify the fracture response, which tends to be concentration-dependent and showed improved fracture response at $2 \%$ concentration for CS WMAadditive type, but this response was opposite for the FT and WB types with the only exception of $6 \% \mathrm{WB}$ concentration [43]. Additional research by [44] substantiated a detrimental ductile response of high-polymer modified bitumens with SBS (i.e., 3-5\% concentration by weight of base bitumen). In fact, it was found that both in unaged and PAV-aged conditions, the CTOD values for the SBS-modified samples had lower ductile performance (i..e, lower CTOD values), with one single exception to this trends for a SBS-blend (A5), which had the same CTOD value, measured at deformation rate of $50 \mathrm{~mm} / \mathrm{min}$, as the base bitumen after long-term ageing protocol. Additional research on PMB-bitumen modification through various concentrations of RAP binder (i.e., $0 \%, 15 \%, 25 \%$, and $40 \%$ ) indicated that the higher concentrations of this bitumen modified negatively affect the intermediate temperature response in terms of the ductile properties measured through DENT and elastic recovery tests [45]. Conversely, [46] found that for low-SBS polymer concentrations the fracture performance after PAV-ageing seems comparable and at some instances superior to that of base bitumen for concentrations ranging from $1.2 \%$ to $1.8 \%$ by weight of base bitumen. It was also found that the superior response at RTFO ageing conditions is not equaled by that of PAV-aged materials, indicating a detrimental effect of artificial ageing on the fracture response for these material combinations. 


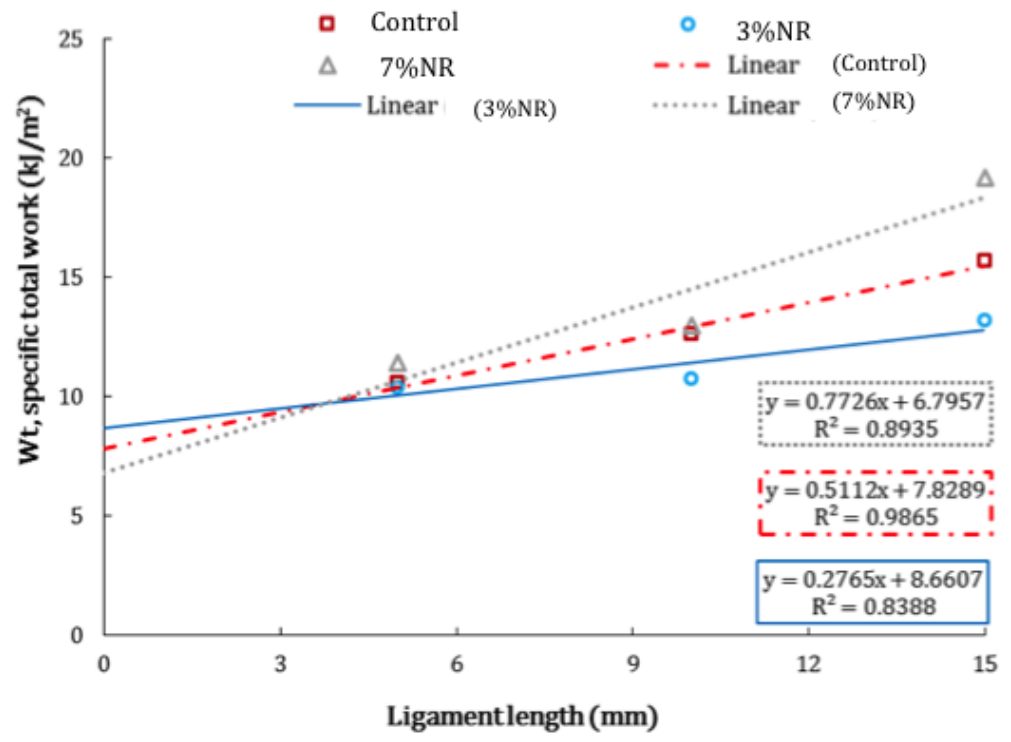

(a)

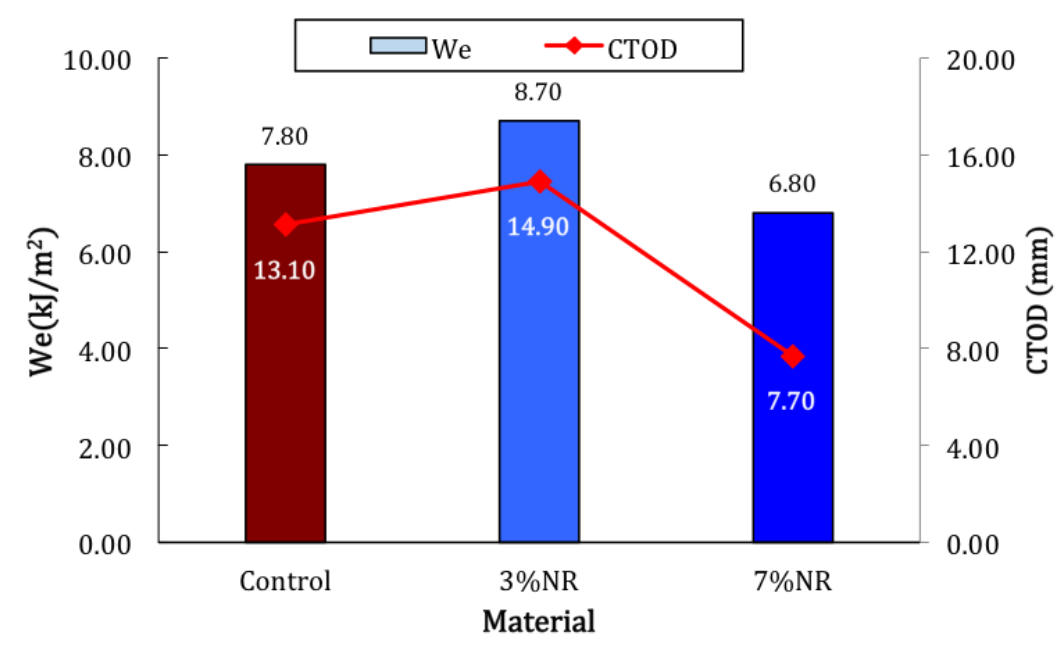

(b)

Figure 10. (a) The specific total work of fracture $\left(W_{t}\right)$ and plastic work of failure $\left(\beta w_{p}\right)$, (b) essential work of failure $\left(W_{e}\right)$, and critical crack opening displacement (CTOD) for neat bitumen and NRMBs. 
Table 4. Summary of peak load and deformation to failure for neat binder and NRMBs.

\begin{tabular}{|c|c|c|c|c|c|c|}
\hline \multirow[t]{3}{*}{ Material } & \multicolumn{6}{|c|}{ DENT insert length (mm) } \\
\hline & \multicolumn{2}{|r|}{5} & \multicolumn{2}{|c|}{10} & \multicolumn{2}{|c|}{15} \\
\hline & $\begin{array}{c}\text { Peak } \\
\text { Load (N) }\end{array}$ & $\begin{array}{c}\text { Failure } \\
\text { Deformation } \\
\text { (mm) }\end{array}$ & $\begin{array}{c}\text { Peak Load } \\
\text { (N) }\end{array}$ & $\begin{array}{c}\text { Failure } \\
\text { Deformation } \\
\text { (mm) }\end{array}$ & $\begin{array}{c}\text { Peak Load } \\
\text { (N) }\end{array}$ & $\begin{array}{c}\text { Failure } \\
\text { Deformation } \\
\text { (mm) }\end{array}$ \\
\hline Control & 30 & 34.8 & 40 & 67.2 & 46 & 118 \\
\hline Control $+3 \%$ NR & 29 & 47.2 & 37 & 80.6 & 42 & 134 \\
\hline Control $+7 \%$ NR & 44 & 32 & 57 & 56.2 & 66 & 94 \\
\hline
\end{tabular}

\section{Conclusions}

The laboratory investigation described in this paper assessed the effects of NR on the rheological and performance-related characteristics of modified bitumens (NRMB). This was achieved through a comprehensive laboratory programme incorporating the evaluation of NR effects on bitumen rheology and the evaluation of fatigue cracking, thermal cracking, permanent deformation and fracture properties of the NRMB. Two NRMB blends were manufactured with $3 \%$ and $7 \%$ NR by mass of binder using a 40/60-penetration grade base bitumen (control). The test methods included: (1) Dynamic Shear Rheometer (DSR) master curves and Black Space diagrams together with Bending Beam Rheometer (BBR) tests for rheological assessment over a wide temperature range; (2) Linear Amplitude Sweep (LAS) tests for assessing fatigue at intermediate temperatures; (3) Multiple Stress Creep Recovery (MSCR) tests for permanent deformation at high temperature; and (4) the evaluation of fracture properties at intermediate temperatures using the Double Edged-Notched Test (DENT) test. Based on the experimental results and analysis, the following main conclusions can be drawn:

1) The effects of NR on the bitumen rheology produced changes in the rheological parameters $\left(G^{*}\right.$ and $\left.\delta\right)$ that were captured via the master curves and Black Diagrams. It was observed that increased NR content produced significant increase of the stiffness of NRMBs (higher $G^{*}$ ) that was particularly pronounced at high testing temperatures. Similarly, the decrease of $\delta$ values are consistent with the results of $G^{*}$ and the Black Diagrams showed a shift of the NRMBs curves towards a zone related to more elastic response in comparison to the base control bitumen. Overall, these results indicated a substantial level of modification of the base bitumen that relates to more elastic NRMBs with higher resistance to permanent deformation as further substantiated with MSCR testing. 
2) The rheological characterisation at low-temperatures found that: (i) NR induced positive effects on the

3) The fatigue performance of the NRMB blends assessed by means of the LAS testing indicated that NR increased the fatigue life of the base bitumen by a significant extent at the intermediate temperatures considered $\left(15^{\circ} \mathrm{C}\right.$ and $\left.25^{\circ} \mathrm{C}\right)$. This impact on fatigue life was consistent for both strain levels $(\gamma=2.5 \%$ for thin pavement structures and $\gamma=5.0 \%$ for thick pavement structures) but it was more prominent at the lower strain level. In general, the results showed a higher number of cycles to reach failure $(N f)$ for $7 \%$ NRMB as compared to those of control bitumen and 3\% NRMB. These findings were consistent for the temperatures considered, which suggests positive effects of NR on bitumen modification with regard to fatigue cracking.

4) Positive effects of NR on the permanent deformation resistance were observed indicating an increased resistance for both NR contents considered. The maximum resistance was reached for the $7 \% \mathrm{NR}$ content as it related to the highest $R$-values and lowest $J_{n r}$ parameter for all combinations studied. These results substantiated the positive influence of NR on the rutting response for the NRMBs when compared to that of base bitumen for both unaged and RTFO-aged materials. However, some detrimental effects on the polymer structure (crosslink of the NR molecules) of the short-term ageing regime did likely occur as observed by slightly reduced R-values for the RTFO-aged materials. The stress effects on the NRMBs resistance to rutting indicated that the improvement of this material response was predominant for higher stresses $(3.2$ $\mathrm{kPa})$ in contrast to the lower stress considered $(0.1 \mathrm{kPa})$. Nevertheless, the stress sensitivity $\left(J_{n r-d i f f}\right)$ increased with NR addition to the base bitumen, reaching a maximum for $3 \%$ NR content for both ageing conditions, which is expected as a result of high-content polymeric modification of bitumen, such as that provided by Styrene-Butadiene-Styrene (SBS) in polymer modified mixtures (PMA).

5) The NRMBs exhibited a limited fracture response as observed with the DENT test results in terms of the fracture properties of $W_{t}, W_{e}, \beta w_{p}$, and CTOD. In practical terms, based on the material combinations 
considered, these results suggest that NR content should not exceed $3 \%$ when attempting to minimize

fatigue cracking and improve fracture performance at the micro scale. Similarly, other NR dosages should be explored with different base bitumen types than those included in this investigation for further validation of fracture properties.

Overall, the evidence obtained through the experimental programme and materials tested substantiates some performance-related benefits of NR and its suitability for applications in warmer countries, such as Thailand or those encountered in South East Asia where NR is produced and widely available, for which fatigue and permanent deformation of pavements represents the major challenges for mixture design, performance and durability. Furthermore, a possible increase in the current limits of NR use for road infrastructure is envisioned as a practical application of this research study, when complemented with additional future studies. Similarly, these results encourage use of NR in other countries aiming at promoting sustainable road infrastructure.

Some recommendations for future work include:

- Although storage stability of the samples has not been studied by this research work, previous work by [47] substantiated that NR contents of up to $6 \%$ exhibit stable performance for use at high temperatures. Furthermore, [48] demonstrated with factual evidence that contents up to $9 \%$ can have satisfactory storage stability and indicated that this property is largely dependent on the NR concentration. Similar findings were reported by [49], who reported satisfactory storage stability for blends subjected to conditioning for 72 hours at $163^{\circ} \mathrm{C}$. Therefore, future studies might add value to the characterization of NRMB by incorporating the storage stability results.

- In terms of the complexity of bitumen modification through NR in comparison to other polymers, our experience and that reported by previous research indicates $[50,51]$ the following: Overall, it is harder to mix NR latex than other polymers because of its liquid nature in contrast to others being capsules or grinded materials (solid-like). Furthermore, the fact that NRL contains "water" in the latex, and have high ammonia content makes it hard to produce blending due to the physical effects (i.e., frothing and foaming), in addition to the strong smell produced by the ammonia. For these reasons, the liquid NRL is gradually added to the base bitumen at small portions, which allows for reducing the air bubbles and evaporation. This is aided by manual stirring to minimize the foaming of the rubber to reach the top head of the mixing machine. Certainly, this procedure means more time consumption than other polymers but it allows for homogeneous blend if carried out cautiously by future researchers. 


\section{Acknowledgements}

Jarurat Witinapanit expresses deep gratitude for the sponsorship offered by the Thailand government to conduct M.Sc. studies at the University of Nottingham. Similarly, Juan S. Carvajal-Munoz acknowledges the valuable support provided by the Universidad del Norte (CCBUNDDA/12/2016), and Colciencias-Colfuturo (Colombia) (728 National Call, 2015) to conduct Ph.D. studies at the University of Nottingham, United Kingdom.

\section{References}

[1] Rubber Journal Asia. (2017). Malaysia still evaluating feasibility of rubberised roads in pilot projects. [online] Available at: http://rubberjournalasia.com/malaysia-still-evaluating-feasibility-of-rubberised-roadsin-pilot-projects/ [Accessed 20 Feb. 2019].

[2] Reuters. (2014). Malaysia plans rubber roads as producers struggle to lift prices. [online] Available at: https://www.reuters.com/article/asia-rubber-anrpc-idUSL3N0S81ZH20141013 [Accessed 20 Feb. 2019].

[3] Gawel, I., Stepkowski, R. and Czechowski, F. (2006). Molecular Interactions between Rubber and Asphalt. Industrial \& Engineering Chemistry Research, 45(9), pp.3044-3049.

[4] Celauro, B., Celauro, C., Lo Presti, D. and Bevilacqua, A. (2012). Definition of a laboratory optimization protocol for road bitumen improved with recycled tire rubber. Construction and Building Materials, 37 , pp.562-572.

[5] Lo Presti, D. (2013). Recycled Tyre Rubber Modified Bitumens for road asphalt mixtures: A literature review. Construction and Building Materials, 49, pp.863-881.

[6] Subhy, A., Lo Presti, D. and Airey, G. (2015). An investigation on using pre-treated tyre rubber as a replacement of synthetic polymers for bitumen modification. Road Materials and Pavement Design, 16(sup1), pp.245-264.

[7] Heitzman, M. (1992). Design and construction of asphalt paving materials with crumb rubber modifier. Transportation Research Record, 1339.

[8] Yildirim, Y. (2007). Polymer modified asphalt binders. Construction and Building Materials, 21(1), pp.6672.

[9] Mashaan, N., Ali, A., Koting, S. and Karim, M. (2013). Performance Evaluation of Crumb Rubber Modified Stone Mastic Asphalt Pavement in Malaysia. Advances in Materials Science and Engineering, 2013, pp.1-8.

[10] Takallou, H. and Hicks, R. (1988). Development of improved mix and construction guidelines for rubber modified asphalt pavements. [Washington, D.C.]: [Transportation Research Board].

[11] Fontes, L., Trichês, G., Pais, J. and Pereira, P. (2010). Evaluating permanent deformation in asphalt rubber mixtures. Construction and Building Materials, 24(7), pp.1193-1200.

[12] Pasquini, E., Canestrari, F., Cardone, F. and Santagata, F. (2011). Performance evaluation of gap graded Asphalt Rubber mixtures. Construction and Building Materials, 25(4), pp.2014-2022.

[13] Wang, H., Dang, Z., Li, L. and You, Z. (2013). Analysis on fatigue crack growth laws for crumb rubber modified (CRM) asphalt mixture. Construction and Building Materials, 47, pp.1342-1349.

[14] Kaloush, K. (2014). Asphalt rubber: Performance tests and pavement design issues. Construction and Building Materials, 67, pp.258-264. 
[15] Al-Mansob, R., Ismail, A., Alduri, A., Azhari, C., Karim, M. and Yusoff, N. (2014). Physical and rheological properties of epoxidized natural rubber modified bitumens. Construction and Building Materials, 63, pp.242-248.

[16] Al-Mansob, R., Ismail, A., Yusoff, N., Albrka, S., Azhari, C. and Karim, M. (2016). Rheological characteristics of unaged and aged epoxidised natural rubber modified asphalt. Construction and Building Materials, 102, pp.190-199.

[17] Airey, G. (2002). Use of Black Diagrams to Identify Inconsistencies in Rheological Data. Road Materials and Pavement Design, 3(4), pp.403-424.

[18] Bahia, H., and Teymourpour, P. (2014). Linear Amplitude Sweep Test: Binder Grading Specification and Field Validation. Asphalt Binder Expert Task Group Meeting, Baton Rouge, LA, September 16, 2014.

[19] AASHTO TP101. (2014). Estimating damage tolerance of asphalt binders using the linear amplitude sweep.

[20] Hintz, C., Velasquez, R., Johnson, C. and Bahia, H. (2011). Modification and Validation of Linear Amplitude Sweep Test for Binder Fatigue Specification. Transportation Research Record: Journal of the Transportation Research Board, 2207(1), pp.99-106.

[21] Ding, H., Rahman, A., Li, Q. and Qiu, Y. (2017). Advanced mechanical characterization of asphalt mastics containing tourmaline modifier. Construction and Building Materials, 150, pp.520-528.

[22] Nuñez, J., Leonel, E. and Faxina, A. (2016). Fatigue characteristics of modified asphalt binders using fracture mechanics. Engineering Fracture Mechanics, 154, pp.1-11.

[23] Lytton, R. L., Chen, C. W., \& Little, D. N. (2001). Microdamage healing in asphalt and asphalt concrete, volume IV: A viscoelastic continuum damage fatigue model of asphalt concrete with microdamage healing (No. FHWA-RD-98-144).

[24] Bahia, H., Tabatabaee, H., Mandal, T. and Faheem, A. (2013). Field evaluation of Wisconsin modified binder selection guidelines - phase II. Madison: Wisconsin Department of Transportation.

[25] Test Method LS-299. (2001). Method of test for the determination of asphalt cement's resistance to ductile failure using Double Edge Notched Tension Test (DENT). Ministry of Transportation, Ontario, Canada.

[26] Jitsangiam, P., Chindaprasirt, P. and Nikraz, H. (2013). An evaluation of the suitability of SUPERPAVE and Marshall asphalt mix designs as they relate to Thailand's climatic conditions. Construction and Building Materials, 40, pp.961-970.

[27] Charoentham, N. and Kanitpong, K. (2012). Development of Proposed Performance Grading System for Asphalt Binder used in Thailand. Asian Transport Studies, 2(2), pp.121-138.

[28] AASHTO (2009). Standard method of test for multiple stress creep recovery (MSCR) test of asphalt binder using a dynamic shear rheometer (DSR). American Association of State Highway and Transportation Officials, Washington, DC.

[29] AASHTO (2012). Standard method of test for determining the flexural creep stiffness of asphalt binder using the Bending Beam Rheometer (BBR)(AASHTO T313-12-UL). American Association of State Highway and Transportation Officials, Washington, DC.

[30] Anderson, R. M., King, G. N., Hanson, D. I., \& Blankenship, P. B. (2011). Evaluation of the relationship between asphalt binder properties and non-load related cracking. Journal of the Association of Asphalt Paving Technologists, 80 . 
[31] McDaniel, R. S., \& Anderson, R. M. (2001). Recommended use of reclaimed asphalt pavement in the Superpave mix design method: technician's manual (No. Project D9-12 FY'97). National Research Council (US). Transportation Research Board.

[32] British Standard (2014). Bitumen and Bituminous binders Determination of resistance to hardening under influence of heat and air - part 1: RTFOT method. BS EN 12607-1. British Standards Institution, London, United Kingdom.

[33] British Standard (2000). Bitumen and bituminous binders - Accelerated long-term ageing conditioning by a Pressure Ageing Vessel (PAV), BS EN 14769:2012. British Standards Institution, London, United Kingdom.

[34] Marasteanu, M. O., \& Basu, A. (2004). Stiffness m-value and the low temperature relaxation properties of asphalt binders. Road materials and pavement design, 5(1), 121-131.

[35] Cuciniello, G., Leandri, P., Filippi, S., Presti, D. L., Losa, M., \& Airey, G. (2018). Effect of ageing on the morphology and creep and recovery of polymer-modified bitumens. Materials and Structures, 51(5), 136.

[36] Cuciniello, G., Leandri, P., Presti, D. L., Losa, M., \& Airey, G. (2019). Investigating the Effect of Artificial Ageing on the Creep and Recovery of SBS-Modified Bitumen. In MATEC Web of Conferences (Vol. 271, p. 03009). EDP Sciences.

[37] White, G. (2015). Grading of Australian bitumen by multiple stress creep recovery. Road and Transport Research, vol. 24, no. 4, pp.30-44

[38] White, G. (2016). Grading highly modified binders by multiple stress creep recovery. Road Materials and Pavement Design, 18(6), pp.1322-1337. 10.

[39] AASHTO. (2010). Standard specification for performance-graded asphalt binder using multiple stress creep recovery (MSCR) test. American Association of State Highway and Transportation Officials AASHTO designation: MP 19-10, Washington, D.C.

[40] Subhy, A., Presti, D. L., \& Airey, G. (2017). Evaluation of the fracture performance of different rubberised bitumens based on the essential work of fracture. Engineering Fracture Mechanics, 179, 203-212.

[41] Agbovi, Henry Kwame (2012). Effects of low temperatures, repetitive stresses and chemical aging on thermal and fatigue cracking in asphalt cement pavements on highway 417. (M.Sc. Thesis). Queen's University Kingston, Ontario, Canada

[42] Singh, D. and Girimath, S. (2016). Influence of RAP sources and proportions on fracture and low temperature cracking performance of polymer modified binder. Construction and Building Materials, 120, pp.10-18.

[43] Kataware, A. V., \& Singh, D. (2018). Evaluation of intermediate temperature cracking performance of warm mix additive modified asphalt binders. Construction and Building Materials, 184, 165-176.

[44] Paliukaite, M., Verigin, M., \& Hesp, S. (2015). Double-edge-notched tension testing of asphalt cement for the control of cracking in flexible asphalt pavements. Bituminous mixtures and pavements VI, 13.

[45] Singh, D., Girimath, S., \& Ashish, P. K. (2019). Effect of recycled asphalt binder on high and intermediate temperature performance of polymer modified asphalt binder. International Journal of Pavement Research and Technology, 12(5), 486-496.

[46] Kanabar, N. (2010). Comparison of ethylene terpolymer, styrene butadiene, and polyphosphoric acid type modifiers for asphalt cement (Doctoral dissertation). Queens University, Canada.

[47] Al-Mansob, R. A., Ismail, A., Alduri, A. N., Azhari, C. H., Karim, M. R., \& Yusoff, N. I. M. (2014). Physical and rheological properties of epoxidized natural rubber modified bitumens. Construction and Building Materials, 63, 242-248. 
[48] Al-Mansob, R. A., Ismail, A., Md Yusoff, N. I., Azhari, C. H., Karim, M. R., Alduri, A., \& Baghini, M. S. (2014). Rheological characteristics of epoxidized natural rubber modified bitumen. In Applied Mechanics and Materials (Vol. 505, pp. 174-179). Trans Tech Publications Ltd.

[49] Usman, A., Izzaty, N., Ibrahim, R., Sutanto, M. H., \& Sunarjono, S. (2019). Storage Stability and Morphology of Latex Modified Bitumen. International Journal of Innovative and Exploring Engineering (IJITEE), ISSN, 2278-3075.

[50] Biro, S., \& Fazekas, B. (2012). Asphalt rubber versus other modified bitumens. In The Asphalt Rubber 2012 Conference Proceedings, Munich (pp. 351-366).

[51] Porto, M., Caputo, P., Loise, V., Eskandarsefat, S., Teltayev, B., \& Oliviero Rossi, C. (2019). Bitumen and bitumen modification: A review on latest advances. Applied Sciences, 9(4), 742. 
September $8^{\text {th }} 2020$

Respected

Dr. Dimitrios Aggelis

Editor

Construction and Building Materials, ELSEVIER

Dear Dr. Aggelis:

Hereby I kindly submit the responses to the comments raised by the reviewers to the scientific article entitled: "Performance-Related and Rheological Characterisation of Natural Rubber Modified Bitumen" by Jarurat Wititanapanit, Juan S. Carvajal and Gordon Airey. Trough this communication I would like to inform you that this article is original in nature and that it has not been and will not be presented to any other journal or academic event. In the same way I allow myself to confirm that the authors of this article assume collective responsibility for the information contained in the manuscript.

All the comments raised by the reviewers have been addressed accordingly and the responses provided on a point-bypoint basis in this letter (answered in blue color). Similarly, the revised paper with track changes has been included as part of the documents in this submission.

\section{Reviewer \#1}

Good paper on NR modified asphalt. Below are my personal comments for your reference.

1. The basic information on NR is missing. NR latex or NR powder? And the molecular weight?

Detailed information included in the updated manuscript with track changes on page 2 and 3.

2. The specific DSR equipment should be given in experimental sections. TA xx? Malvern xx? Anton Paar MCR

Dynamic Shear Rheometer (DSR) devices included a Bohlin Gemini ${ }^{\circledR}$ used for master curves, and LAS; a Bohlin $\mathrm{CVO}{ }^{\circledR}$ used for master curves and MSCR testing. This is now included in the revised manuscript, pages 4 and 8 .

3. P6 Line 15. As recommended by AASHTO T315, for low temperature DSR tests, $8 \mathrm{~mm}$ parallel plates should be firstly heated to $64^{\circ} \mathrm{C}$ or upper temperature before the installation of asphalt sample. In this case, the adhesion between asphalt and plates can be guaranteed.

These guidelines were carefully followed for the experimental procedure to ensure proper bitumen-plate adhesion and restrict delamination.

4. P8 Line 47. Please pay attention to the latest AASHTO specification, 20 cycles are used for $0.1 \mathrm{kPa}$ creep stress.

Corrected in test method description. Page 8 .

5. As presented in your master curves, NR molecules does not seem to greatly crosslink to each other since one could not see the phase angle plateau region, which can be easily found in well dispersed SBS modified asphalt. Besides, the reviewer also suspects that the neat bitumen 40/60 could also be the reason. If softer bitumen was used, the NR molecular chains might have a better elastic behavior.

This is a very logical reasoning and we agree with the idea of softer bitumen providing improved crosslink that lead to better elastic behavior. However, the fact we used a harder bitumen inevitably produced the viscoelastic response evinced in the discussed results.

6. If possible, it would be better to include -6 and $-12{ }^{\circ} \mathrm{C}$ BBR results to make the calculation of critical temperatures more precisely. As one can see, your S and m-value results at -18 and $-24^{\circ} \mathrm{C}$ are over the critical values $300 \mathrm{MPa}$ and 0.3 .

Unfortunately, the only BBR data collected included those temperatures presented in the paper. However, these data allows for understanding the effects of NR at the low-testing temperatures and aids distinguishing whether the material is suitable for colder or warmer regions. We agree it would be quite interesting to study additional temperature for a more comprehensive comparison, but current circumstances of laboratory closures and the fact the research project finished already hinder the possibility of including additional testing data, for which we offer sincere apologies to the reviewer.

7. After RTFO aging, R\% reduced for both NR samples. Please explain. Explained in text, page 17:

"The reduction in the percent recovery $(\% \mathrm{R})$ is explained by the possible damaging of the NR crosslink structure (i.e., polymer network stability) induced by this short-terms ageing protocol, which inevitably 
affects the permanent deformation response of the NRMBs at both concentrations studied. Under this oxidative condition, the hardened bitumen phase is responsible for the most part of the rheological response. Previous research found similar results of dropping recovery values when polymer-modified bitumen blends were subjected to artificial ageing cycles in both RTFO and PAV (Cuciniello et al. 2018, Cuciniello et al. 2019)".

Cuciniello, G., Leandri, P., Filippi, S., Presti, D. L., Losa, M., \& Airey, G. (2018). Effect of ageing on the morphology and creep and recovery of polymer-modified bitumens. Materials and Structures, 51(5), 136.

Cuciniello, G., Leandri, P., Presti, D. L., Losa, M., \& Airey, G. (2019). Investigating the Effect of Artificial Ageing on the Creep and Recovery of SBS-Modified Bitumen. In MATEC Web of Conferences (Vol. 271, p. 03009). EDP Sciences.

8. The possible reason that $7 \%$ NRMB presents poor fracture performance could be the of discrete NR molecules, which are not bounded together, which caused stress concentration inside the asphalt samples. The authors are encouraged to cite some references on DENT results for SBS modified asphalt. Through the comparison, one could understand easier for NRMBs.

This reasoning proposed by the reviewer is agreed and has been added to the manuscript, along with some references of DENT results for SBS-modified bitumen.

Included in Page 19 and Page 20:

"The results observed for the maximum concentration of NR in the NRMBs might be associated by the detrimental side effects produced by the artificial ageing regimes (i.e., RTFO and PAV) that are required prior testing for DENT. More precisely, as discussed before, the polymer network or cross-link of the NR molecules seems to be disintegrated by the short- and long-term ageing, which results in stress concentration in the bitumen matrix. Previous research on fracture response of SBS-modified bitumen through DENT testing found that high polymer concentrations (i.e. higher than $2 \%$ ) tend to have poorer fracture performance in comparison to reasonably low contents of modifiers. In fact, the use of WMA additives such as FischerTropsch (FT), chemical surfactants (CS) and water-based (WB) have the ability to modify the fracture response, which tends to be concentration-dependent and showed improved fracture response at $2 \%$ concentration for CS WMA-additive type, but this response was opposite for the FT and WB types with the only exception of 6\% WB concentration (Kataware \& Singh, 2018). Additional research by Paliukaite et al. (2015) substantiated a detrimental ductile response of high-polymer modified bitumens with SBS (i.e., 3-5\% concentration by weight of base bitumen). In fact, it was found that both in unaged and PAV-aged conditions, the CTOD values for the SBS-modified samples had lower ductile performance (i..e, lower CTOD values), with one single exception to this trends for a SBS-blend (A5), which had the same CTOD value, measured at deformation rate of $50 \mathrm{~mm} / \mathrm{min}$, as the base bitumen after long-term ageing protocol. Additional research on PMB-bitumen modification through various concentrations of RAP binder (i.e., $0 \%, 15 \%, 25 \%$, and $40 \%$ ) indicated that the higher concentrations of this bitumen modified negatively affect the intermediate temperature response in terms of the ductile properties measured through DENT and elastic recovery tests (Singh et al., 2019). Conversely, Kanabar (2010) found that for low-SBS polymer concentrations the fracture performance after PAV-ageing seems comparable and at some instances superior to that of base bitumen for concentrations ranging from $1.2 \%$ to $1.8 \%$ by weight of base bitumen. It was also found that the superior response at RTFO ageing conditions is not equaled by that of PAV-aged materials, indicating a detrimental effect of artificial ageing on the fracture response for these material combinations".

Kataware, A. V., \& Singh, D. (2018). Evaluation of intermediate temperature cracking performance of warm mix additive modified asphalt binders. Construction and Building Materials, 184, 165-176.

Paliukaite, M., Verigin, M., \& Hesp, S. (2015). Double-edge-notched tension testing of asphalt cement for the control of cracking in flexible asphalt pavements. Bituminous mixtures and pavements VI, 13 .

Singh, D., Girimath, S., \& Ashish, P. K. (2019). Effect of recycled asphalt binder on high and intermediate temperature performance of polymer modified asphalt binder. International Journal of Pavement Research and Technology, 12(5), 486-496.

Kanabar, N. (2010). Comparison of ethylene terpolymer, styrene butadiene, and polyphosphoric acid type modifiers for asphalt cement (Doctoral dissertation). Queens University, Canada.

\section{Reviewer \#3}


The paper relates well to the topics of this Journal, and I did not find plagiarism or republication problems. The paper is not exciting because it does not seem to bring sufficiently new ideas, even though the authors explained that few papers have worked in the modifications of bitumen with natural rubber (I found 78 documents on that topic in a quick search). Nevertheless, the article accomplishes all other formal objectives of a research paper (i.e., a well-designed methodology, correct analysis and discussion of results, conclusions are based on the results of the work). Overall, this paper can be accepted for publication after minor changes.

Some questions to be analyzed or explained in more detail:

1. The number of binders studied was short (only the base binder and two NR modified binders). If authors intend to use NR for bitumen modification, they should have compared the results obtained with those of a commercial modified PMB. Another alternative is to modify the same base bitumen with SBS or recycled rubber since those are the materials used for asphalt binder modification. If authors can present one of those PMB materials, the quality of the paper would be significantly improved.

This comment is reasonable and valid, however, the main objective was investigating the effects of NR on bitumen modification from a comprehensive set of experimental methods helping to understand a wide range of properties at high-intermediate-low testing conditions, and for this reason the experimental programme included the set of materials already presented. On the other hand, at this moment it is not possible for the authors to conduct further manufacturing and testing on bitumen samples and NRMBs as laboratories are currently closed due to current COVID circumstances and the fact the experimental work associated to this research project has been completed, for which the authors present sincere apologies.

2. More information on the natural rubber should be given (Is it liquid or solid? What are its origin and global properties?). If this is the novelty of the paper, the authors should clearly demonstrate its importance.

Physicochemical properties and a more detailed description of the natural rubber have been included in the materials section. Page 2 and 3.

3. The selection of a hard bitumen for bitumen modification is not usual. Moreover, the amounts or NR used were arbitrary (i.e., polymer modification is usually made with up to $5 \%$ polymer, while modification with recycled rubber can use up to $22 \%$ rubber). Please give additional details on these points.

One of the most commonly used penetration grade bitumen in South East Asia is AC60/70, for that reason and to evaluate more critical conditions of the materials, an AC50/70 was used for the investigation of the NR effects in the sense this bitumen type does not massively differ from the 60/70 type and due to material availability in the UK at the time the research was conducted. Regarding concentrations of NR, the values were not arbitrary as these considered the typical amounts normally used in Southeast Asia and these were selected in accordance with previously published academic literature, including, for instance, the following references:

- $\quad$ Abdulrahman, S., Hainin, M. R., Idham, M. K., Hassan, N. A., Warid, M. N. M., Yaacob, H., ... \& Puan, O. C. (2019, May). Physical properties of warm cup lump modified bitumen. In IOP Conference Series: Materials Science and Engineering (Vol. 527, No. 1, p. 012048). IOP Publishing.

a. These authors incorporated concentrations of $2.5 \%, 5.0 \% .7 .5 \%$, and $10 \%$ cup lump rubber to $60 / 70$ base bitumen.

- Azahar, N. M., Hassan, N. A., Putrajaya, R., Hainin, M. R., Puan, O. C., Shukry, N. A. M., \& Hezmi, M. A. (2019, January). Engineering properties of asphalt binder modified with cup lump rubber. In IOP Conference Series: Earth and Environmental Science (Vol. 220, No. 1, p. 012014).

a. Using a $60 / 70$ as base bitumen, the authors incorporated cup lump rubber at $5 \%, 10 \%$, and $15 \%$ concentrations by weight of base bitumen.

- $\quad$ Bakar, S. K. A., Abdulah, M. E., Kamal, M. M., Abd Rahman, R., Hadithon, K. A., Buhari, R., \& Tajudin, S. A. A. (2018). Evaluating the rheological properties of waste natural rubber latex modified binder. In E3S Web of Conferences (Vol. 34, p. 01037). EDP Sciences.

a. This investigation studied concentrations of waste NR latex ranging from $5 \%$ to $15 \%$ by weight of base bitumen (penetration grade 80/100)

4. The industrial production of these "new" binders with NR is an issue to be addressed for some possible readers of the paper. Would this NR modified binder have enough storage stability? Is it easier ou harder to modify binders with NR in comparison with other polymers?

This has been added as a recommendation for future work.

Although storage stability of the samples has not been studied in our research work, previous work by AlMansob et al. (2014a) substantiated that NR contents of up to $6 \%$ exhibit stable performance for use at high 
temperatures. Furthermore, Al-Mansob et al. (2014b) demonstrated with factual evidence that contents up to $9 \%$ can have satisfactory storage stability and indicated that this property is largely dependent on the NR concentration. Similar findings were reported by Usman et al. (2019), who reported satisfactory storage stability for blends subjected to conditioning for 72 hours at $163^{\circ} \mathrm{C}$. Therefore, future studied might add value to the characterization of NRMB by incorporating the storage stability results.

Al-Mansob, R. A., Ismail, A., Alduri, A. N., Azhari, C. H., Karim, M. R., \& Yusoff, N. I. M. (2014). Physical and rheological properties of epoxidized natural rubber modified bitumens. Construction and Building Materials, 63, 242-248.

Al-Mansob, R. A., Ismail, A., Md Yusoff, N. I., Azhari, C. H., Karim, M. R., Alduri, A., \& Baghini, M. S. (2014). Rheological characteristics of epoxidized natural rubber modified bitumen. In Applied Mechanics and Materials (Vol. 505, pp. 174-179). Trans Tech Publications Ltd.

Usman, A., Izzaty, N., Ibrahim, R., Sutanto, M. H., \& Sunarjono, S. (2019). Storage Stability and Morphology of Latex Modified Bitumen. International Journal of Innovative and Exploring Engineering (IJITEE), ISSN, 2278-3075.

In terms of the complexity of bitumen modification through NR in comparison to other polymers, our experience and that reported by previous research indicates (Biro \& Fazekas, 2012; Porto et al., 2019) the following:

Overall, it is harder to mix NR latex than other polymers because of its liquid nature in contrast to others being capsules or grinded materials (solid-like). Furthermore, the fact that NRL contains "water" in the latex, and have high ammonia content makes it hard to produce blending due to the physical effects (i.e., frothing and foaming), in addition to the strong smell produced by the ammonia. For these reasons, the liquid NRL is gradually added to the base bitumen at small portions, which allows for reducing the air bubbles and evaporation. This is aided by manual stirring to minimize the foaming of the rubber to reach the top head of the mixing machine. Certainly, this procedure means more time consumption than other polymers but it allows for homogeneous blend if carried out cautiously.

Biro, S., \& Fazekas, B. (2012). Asphalt rubber versus other modified bitumens. In The Asphalt Rubber 2012 Conference Proceedings, Munich (pp. 351-366).

Porto, M., Caputo, P., Loise, V., Eskandarsefat, S., Teltayev, B., \& Oliviero Rossi, C. (2019). Bitumen and bitumen modification: A review on latest advances. Applied Sciences, 9(4), 742.

5. The low performance at low temperatures, the stress sensitivity in MSCR and the results of NR modified binders in the fractures test are unexpected. Authors mentioned that this is not a problem because these binders would be applied in southern Asia, but this is a limitation of this material. The authors are encouraged to compare this low-performance problem with that of other polymer modified binders, to demonstrate that this is a typicall problem of PMBs (probabily it is not).

This reasoning proposed by the reviewer is agreed and has been added to the manuscript, along with some references of DENT results for SBS-modified bitumen. Included in Page 19 and Page 20

6. Authors can evaluate the elastic recovery of the NR modified binders in MSCR, and present those results. That would be interesting to present an additional property of these binders.

A comprehensive comparison of the permanent deformation results for the materials had already been included and discussed in the paper, in the section of MSCR results. This analysis included the nonrecoverable creep compliance $\left(J_{n r}\right)$, the percent recovery $\left(R\right.$-value) and the stress sensitivity parameter $\left(J_{n r}\right.$ diff). Through these parameters, a clear understanding of the effects of NR on the base bitumen is appreciated, which the authors consider as valid and sufficient to support the rutting performance of the manufactured blends, as it is consistent with many published work studying the permanent deformation response. Therefore, the authors appreciate the comment raised by the reviewer and hope the assessment presented is valid enough to support the aim and objectives of the research paper.

7. Taking into account my previous comments, the approach presented in this paper does not seem to be genuinely innovative, but that is compensated with a well-designed methodology for the study. The organization of the article is right. The description of some materials and methods can be improved, especially the NR description and the fracture test. The discussion of results is good, and further scientific additions to justify the performance at low-temperatures can be added. The conclusions are correct and based on the results of this work. Written English quality is excellent. The objectives are clear, and the paper globally answers those objectives (although the comparison with a commercial PMB is missing).

The authors truly value these final comments about the submitted paper and hope that the changes addressed on the document will satisfy the suggestions provided by the peer reviewers. 
I appreciate your kind attention to this letter and the revised manuscript.

Sincerely,

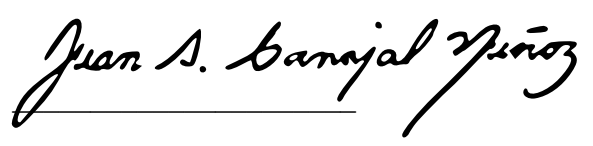

Juan S. Carvajal-Muñoz

PhD Student, Nottingham Transportation Engineering Centre (NTEC). The University of Nottingham

Google Scholar ResearchGate LinkedIn

E-mail: juan.carvajalmunoz@nottingham.ac.uk

Address: NTEC, Pavement Research Building, University Park, Nottingham, NG72RD 


\section{Research highlights}

- The effects of Natural Rubber (NR) were captured through rheological master curves and black diagrams.

- Positive effects on permanent deformation resistance of NR were observed.

- Fatigue cracking resistance was improved by NR addition.

- Thermal cracking resistance $(\Delta T c)$ was satisfactory for 3\% NR content.

- Fracture analysis via DENT test substantiated benefits on cracking performance of $3 \% \mathrm{NR}$ content. 
Click here to access/download RDM Data Profile XML

CONBUILDMAT-D-20-03087_DataProfile.xml 


\section{Declaration of interests}

$\square \mathrm{X}$ The authors of the manuscript titled "Performance-Related and Rheological Characterisation of Natural Rubber Modified Bitumen"declare that they have no known competing financial interests or personal relationships that could have appeared to influence the work reported in this paper.

$\square$ The authors declare the following financial interests/personal relationships which may be considered as potential competing interests: 
Jarurat Wititanapanit: Conceptualization, Methodology, Investigation, FormalAnalysis, Writing- original draft, Project Administration. Juan S. Carvajal-Munoz: Writing- original draft, Writing- review and editing, Visualization, CoSupervision. Gordon Airey: Conceptualization, Methodology, Visualization, Writingreview and editing, Supervision. 


\title{
Performance-Related and Rheological Characterisation of Natural Rubber Modified Bitumen
}

\author{
Jarurat Wititanapanit $^{1}$, Juan S. Carvajal-Munoz ${ }^{2,3, *}$, \& Gordon Airey ${ }^{4}$ \\ ${ }^{1}$ MSc., Researcher, Department of Rural Roads, Ministry of Transport, Bangkhen, Bangkok, Thailand. \\ ${ }^{2}$ Ph.D. Candidate, Nottingham Transportation Engineering Centre (NTEC), University of Nottingham, \\ United Kingdom. \\ ${ }^{3}$ Professor on academic leave, Department of Civil and Environmental Engineering, Universidad del Norte, \\ Barranquilla, Colombia. \\ ${ }^{4}$ Ph.D. Professor and Director of the Nottingham Transportation Engineering Centre (NTEC), University \\ of Nottingham, United Kingdom \\ * Corresponding author: evxjsc@nottingham.ac.uk
}




\title{
Performance-Related and Rheological Characterisation of Natural Rubber Modified Bitumen
}

\begin{abstract}
This paper has beenis motivated by the limited-previous research available evaluating the comprehensive effects of natural rubber bitumen modification (NR) for pavement applications. The study has comprised a $\mathrm{A}$ detailedeomprehensive laboratory programme was carried out to evaluate the influence of NR on the highintermediate-low temperature performance, including rheological characterisations and performance-related tests (fatigue cracking, thermal cracking, fracture and permanent deformation resistance). The main results findings indieated-indicate some beneficial effects of that usingNR on the performance-related response for fatigue and permanent deformation $\mathrm{NR}(3$ and $7 \%)$ induced pesitive effects on the fatigue cracking and rutting performance. Performance Additional benefits were also found in terms ofobserved regarding the -fracture strength andand the thermal cracking resistance $\left(\Delta T_{c}\right)$. The viscoelastic effects of NR on the rheological modification of base bitumen substantiatedproduced significant changes in the viscoelastic characteristicsrheological properties of the control-base bitumen. Overall, the results of this research study encourage the use of NR for pavement applicationsthe use of NR at a concentration of up to $7 \%$ by weight of bitumen proved to be a reasonable option for use in pavement applications, having more substantial benefits in tropical regions in agreement with its predominant effects on the bitumen modification at intermediate-to-high temperature conditions.
\end{abstract}

Keywords: Natural Rubber; Bitumen Modification; Fatigue; Rutting; Fracture; Performance; Rheology.

\section{Introduction}

Natural rubber (NR) is a material produced from native trees (Hevea brasiliensis) in_-South Asia, which is commonly used as a manufactured product either solely or combined with other materials in various industries (e.g., the automobile, textile, insulating membranes, adhesives, footwear and construction)-industries. NR is widely used due-as a consequence of to-its high stretch ratio (i.e., high ductile response or elasticity), its ability to withstand external loading (i.e., permanent deformation resistance) and the high water resistance. Although-In spite of being extensively produced extensively and commercialised from the early 70's, the current bulging stocks of NR eurrently available in Southeast Asian countries and the trends of decreasing trade price have encouragedare gradually encouraging governments and environmental agencies to find-sought for alternative applications in road infrastructure projects $[1,2]$. 
At the same timeSimilarly, the pressing environmental needs for recycling and demands the selection of environmentally friendlyenvironmentally friendly alternatives as surrogates ofte finite natural resources, which has encouraged the supposes the incorporation of waste materials such as recycled tyre rubber [3-6] forin road infrastructure applications, such as the use of recycled tyre rubber [3-6]. At this respect, From-from the late 80's to the early 90 's, research studies have assessed the effects of waste rubber (typically reclaimed from tyres) on bituminous mixtures incorporating multiple approaches and techniques [7-9]. For instance, [10] provided practical guidelines for the design, construction and maintenance of tyre-rubber modified mixtures. More recently, [5] presented a comprehensive literature review of the various benefits associated with the use of recycled tyre-rubber (RTR) with a critical analysis of the existing technologies and specifications that apply to the production process (i.e., production, handling and storage).

As previously mentioned $\underline{\text { Nevertheless, }}$ most investigations of using rubber applications tofor road infrastructure applications have dealt withrelate to RTR effects on bituminous mixtures [11-14] but only limited information is available on the virgin rubber ( for-NR-) in terms of its multi-scale effects on the mixture components and

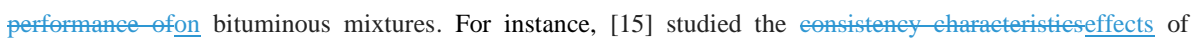
Natural Rubber on Modified Bitumen-Blends (NRMB) based on penetration, softening point and toughness $--_{2}$ which substantiated significantThe main results validated the improvement of the permanent deformation resistance-induced by NR. Similarly, [16] concluded that bitumen modification through -NR ean improveimproves the durability of polymer modified asphalt (PMA) mixtures, and this effect is more prominent when combined through the combination of NR-with peroxy formic acid to produce epoxidised natural rubber that induced a high level of modification of the base bitumen.

There is therefore aThe need to attain further experimental evidence to provide a deeperthat aids understanding tef the effects of NR on bitumen modification and performance of bituminous mixtures supports this research study. Subsequently, this paper aims to investigate the influence exerted by NR on the rheological properties and performance-related characteristics of NRMB (i.e., fatigue cracking, thermal cracking, fracture, and permanent deformation) in terms of fatigue, rutting and fracture strength. The paper incorporates a range of rheological tests and analytical theories to to provide data that help determiningstudy the performance of NR modified bitumen for road infrastructure applications in warmer climates such as those specified in Thailand or similar countries. The paper structure includes a detailed description of the describes the detrils andmaterials and experimental techniques of five binder test methods as well as material details forused for assessing the NRMBs using different NR contents. The rheological and fracturelaboratory data is thenis further analysed 
following in agreement with standardised-relevant analytical approaches and current scientific literature. The paper is completed with a list asseciated with the test methods before compiling a list of the major findings, relevant conclusionsand recommendations for further research.

\section{Materials and Testing Methods}

\subsection{Experimental Programme}

A comprehensive laboratory programme was carried out as shown in Figure 1. with NR by total weight of modified bitumen. The natural rubber latex used for bitumen modification is in liquid form and containing high ammonia (HA), with a chemical structure of cis-1, 4-polyisoprene (also called isoprene)

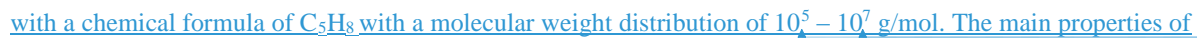
the NR used include those presented in Table 1. A 40/60-penetration grade bitumen was used as the base bitumen (referred to as "control" in the manuscript). with-NR contents of $0 \%, \underline{\underline{3}} \%$ and $7 \%$ by total weight of modified bitumen were used. Five bitumenThe laboratory tests with specific objectives were included in the experimental programme as shownare listed in Figure 1. with each one of the Each tests result correspond to the average of being conducted on three test replicates, with the exception of the DENT test that was (conducted on 2 replicates as per standard guidelines-

\section{Table 1. Natural rubber properties.}

\begin{tabular}{|c|c|c|c|}
\hline Parameters & $\underline{\text { Unit }}$ & Specification & Results \\
\hline$\frac{\text { Total solids content }}{\underline{\text { (TSC) }}}$ & $\%$ by mass & $61.50 \mathrm{~min}$. & $\underline{61.80}$ \\
\hline$\underline{\text { Dry rubber content }}$ & $\%$ by mass & $60.00 \mathrm{~min}$. & $\underline{60.21}$ \\
\hline $\mathrm{pH}$ value at $25.4^{\circ} \mathrm{C}$ & - & $11 \max$. & $\underline{10.48}$ \\
\hline$\frac{\text { Pottassium Hidroxide }}{\underline{\text { Number }(\mathrm{KOH})}}$ & $\%$ by mass & $\underline{0.70 \max }$. & $\underline{0.69}$ \\
\hline $\begin{array}{l}\text { Alkalinity (as ammonia } \\
\text { on total weight) }\end{array}$ & $\%$ by mass & $\underline{0.65-0.75}$ & $\underline{0.68}$ \\
\hline$\underline{\text { Non rubber content }}$ & $\%$ by mass & 1.70 max. & $\underline{1.59}$ \\
\hline$\frac{\text { Volatile fatty acid }}{\text { number }}$ & $=$ & 0.05 max. & $\underline{0.0229}$ \\
\hline $\begin{array}{l}\text { Mechanical stability time } \\
\text { at 55\% TSC }\end{array}$ & $\underline{\text { Sec. }}$. & $\underline{1000-1200}$ & $\underline{1080}$ \\
\hline Specific gravity at $25^{\circ} \mathrm{C}$ & - & $\underline{0.94}$ & $\underline{0.9448}$ \\
\hline$\underline{\text { Magnesium content }}$ & $\mathrm{ppm}$ & 40 max. & $\underline{36.75}$ \\
\hline
\end{tabular}




\begin{tabular}{llll}
\hline Viscosity at $60 \% \mathrm{TSC}$, & $\underline{\mathrm{cps}}$ & -- & $\underline{59.50}$ \\
$\begin{array}{lll}\text { spindle no.1 at } 60 \mathrm{rpm} \\
\text { Coagulum content, } 80\end{array}$ & $\underline{\mathrm{ppm}}$ & $\underline{-}$ & $\underline{20}$ \\
$\underline{\underline{\text { mesh }}}$ & & & \\
\hline
\end{tabular}

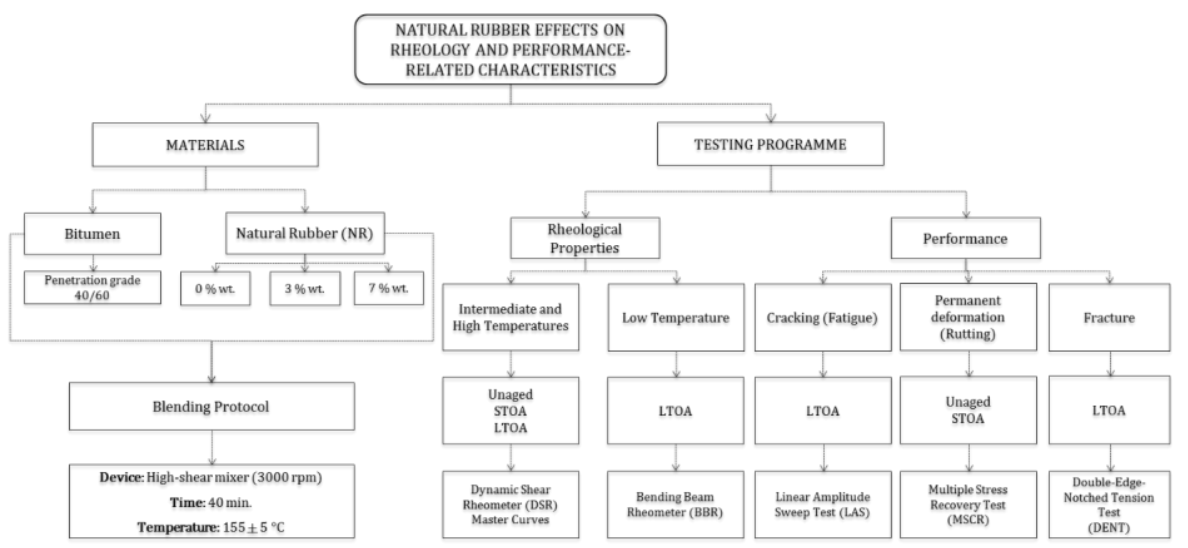

Figure 1. Testing programme for NRMB characterisation. Note: STOA refers to samples subjected to RTFO, LTOA refers to samples subjected to RTFO + PAV.

\subsection{Blending Protocol}

A high-shear mixing approach was followed to guarantee sufficient material dispersion and interaction time between the base bitumen and NR. For this purpose, a high-shear mixer with double-head was used. The procedure for NRMB manufacture included the following steps: (1) The base bitumen (1500g) was preheated in an oven at $150^{\circ} \mathrm{C}$ for 120 minutes. Simultaneously, NR was weighed for mixing at the desired concentration. (2) The base bitumen was extracted from the oven and transferred to a hotplate with the high-shear mixer setup and the ability to keep the temperature at $150^{\circ} \mathrm{C}$. (3) The required amount of NR (45g and $105 \mathrm{~g}$ for $3 \%$ and $7 \%$ blend, respectively) were gradually added to the neat bitumen in order to minimize formation of lumps and air bubbles (due to the presence of water-base liquid) and thereby maximize blending efficiency. (4) The bitumen was manually stirred with a glass rod during NR addition until a fairly homogeneous blend was obtained with minimal formation of air bubbles. (5) Once the blend reached the target temperature on the hotplate $\left(150{ }^{\circ} \mathrm{C}\right)$, checked periodically with a hand thermometer, mechanical blending commenced from low speed (800 rpm) up to a maximum of 2,400 rpm (for 3\% NR content) and 4,200 rpm (for $7 \%$ NR content).

\subsection{Linear Viscoelastic Rheological Characterisation}


Strain-controlled frequency sweep tests were conducted using a Bohlin Gemini ${ }_{\circledR}$ Dynamic Shear Rheometer (DSR)_to determine the viscoelastic properties of the base bitumen and to assess the level of modification induced by NR. For this, parallel-plate geometry was used $(8 \mathrm{~mm}$ and $25 \mathrm{~mm}$ ) with $2 \mathrm{~mm}$ and $1 \mathrm{~mm}$ gap, respectively. The bitumen was heated up in the oven at $150{ }^{\circ} \mathrm{C}$ and then poured into the $8 \mathrm{~mm}$ and $25 \mathrm{~mm}$ moulds and samples were mounted in the DSR after the samples had cooled down and could be removed from the moulds. Low to intermediate temperatures $\left(5^{\circ} \mathrm{C}\right.$ to $35^{\circ} \mathrm{C}$ ) were assessed with the $8 \mathrm{~mm}$ geometry, whereas high temperatures $\left(35^{\circ} \mathrm{C}\right.$ to $75^{\circ} \mathrm{C}$ ) used the $25 \mathrm{~mm}$ geometry. Frequencies from $0.1 \mathrm{~Hz}$ to $10 \mathrm{~Hz}$ were used with a strain level of $0.5 \%$ (within the Linear Viscoelastic Region (LVE), based on amplitude sweep tests). The timetemperature superposition principle (TTSP) was applied for shifting of the rheological data (i.e., $|\mathrm{G} *|$ and $\delta$ ) to produce smooth master curves. The shifting of the data was done using a $25{ }^{\circ} \mathrm{C}$ reference temperature with the application of the Williams-Landel-Ferry (WLF) model. In addition to the master curves of $\left|\mathrm{G}^{*}\right|$ and $\delta$ master curves, a comparison of these parameters was made through Black Space Diagrams and due to their its simplicity (neas it does not require $d$ shifting of rheological data. These rheological parameters were used), a comparison of these parameters was also made using Black Space Diagrams in order to study the relationship between stiffness and viscoelastic properties of the base bitumen and NRMBs [17].

\subsection{Performance-Related Tests}

A DSR was used to characterise the rheological and performance properties of the base bitumen and NRMB blends. In addition to standard oscillatory linear viscoelastic (LVE) frequency sweep tests, the DSR was also used to study the fatigue and permanent deformation performance-related characteristics of the materials. Fatigue cracking was assessed through the Linear Amplitude Sweep (LAS) test and permanent deformation (rutting) by means of the Multiple Stress Creep Recovery (MSCR) test. The fracture characteristics of the binders-materials were also-determined using the Double-Edged Notched Tension (DENT) test. These tests-are considered performance-related tests due to their ability to correlate material response to those of real pavement structures subjected to various loading regimes [18]. The detailed description of these tests is presented in subsequent sections.

\subsubsection{Linear Amplitude Sweep (LAS)}

The LAS test (AASHTO TP101) [19] was used to study the fatigue resistance of the base bitumen and NRMBs as a function of ageing and NR content. The test method is intended for accelerated damage and involves cyclic loading of bitumen samples that are subjected to increasing strain amplitudes. This leads to damage 
accumulation, which is used to assess fatigue performance in terms of the number of cycles required to failure (i.e., a decrease of the initial $\left|G^{*}\right|$ value at the peak shear stress, as per [19]). Aged bitumen samples of $8 \mathrm{~mm}$ diameter and $2 \mathrm{~mm}$ thickness are tested in a strain-controlled mode using the DSR parallel plate geometry. Two test stages are carried outconducted-as follows: (1) The initial stage is non-destructive and involves assessing the undamaged rheological properties of the bitumen samples in terms of the complex modulus $\left(G^{*}\right)$ and phase angle $(\delta)$. This stage is done via a frequency sweep test (i.e., oscillatory loading from $0.2 \mathrm{~Hz}$ to $30 \mathrm{~Hz}$ at $0.1 \%$ strain amplitude). (2) Subsequently, the bitumen sample is subjected to a rest period of 10 s before the onset of the secondary stage. This secondary stage is destructive in nature through applying increasing strain amplitudes (from $1 \%$ to $30 \%$ strain) at a constant frequency of $10 \mathrm{~Hz}$ and is referred to as the continuous oscillatory strain sweep test. In brief, the test parameters include: (1) 100 loading cycles at $0.1 \%$ strain to obtain undamaged material response, and (2) 30 subsequent rounds of 100 cycles from $1 \%-30 \%$ strain, increasing linearly by $1 \%$, for a total of 3,100 cycles of loading [20].

Considering previous literature recommendations for minimizing the risk of delamination (i.e., poor bitumen/plate bonding), caution was taken to select the testing temperature [21]. To control this isstredelamination issues, the failure plane of the sample was checked at the end of the test to identify the typical torsional-fatigue failure of each specimen (i.e., circumferential crack) [22]. The temperature for LAS test was set as $-15^{\circ} \mathrm{C}$ and $25{ }^{\circ} \mathrm{C}$ for all materials, based on previous literature studying fatigue at intermediate temperatures [23]. The selection of two test temperatures was considered to assess the effects of this factor on the materials' fatigue response. In this study, two strain levels were considered to take into account both "strong" and "weak" pavement structures. For a "strong" layer with thickness higher than $100 \mathrm{~mm}$, a low strain $(\gamma=2.5 \%)$ was selected. Similarly, for a "weak" layer with thickness lower than $100 \mathrm{~mm}$, a higher strain $(\gamma=$ $5.0 \%$ ) was considered [24].

Viscoelastic continuum damage (VECD) mechanics, adopting Schapery's theory, was used to simulate damage growth and thus predict fatigue life as a function of strain (Equation 3). It is based on the simplified classic fatigue law (Equation 1) with $A$ and $B$ being obtained from the mathematical relationship between strain $(\gamma)$ and cycles to failure $\left(N_{f}\right)$ as shown in Equation 2,

$$
\begin{gathered}
N_{f}=A\left(\gamma_{\max }\right)^{B} \\
A=\frac{f\left(D_{f}\right)^{k}}{k\left(\pi \frac{I_{D}}{\left|G^{*}\right|} C_{1} C_{2}\right)^{\alpha}}\left|G^{*}\right|^{-\alpha}
\end{gathered}
$$


Where,

$k=1+\left(1-C_{2}\right) \alpha$,

$f$ is the loading frequency, $\mathrm{Hz}$,

$\left|G^{*}\right|$ is the undamaged complex shear modulus,

$\gamma_{\max }$ is the maximum expected binder strain for a given pavement structure in $\%$,

$D_{f}$ is the damage accumulation at failure, defined as the $D(t)$ corresponding to the reduction in initial $\left|G^{*}\right|$ at the peak shear stress.

\subsubsection{Double-Edged Notched Tension (DENT)}

The fracture characteristics in the ductile state of bitumen/NRMBs were studied following the Canadian Standard (Test Method LS-299) [25]. The by means of the essential work of fracture required to generate new surfaces was studied and determined through the DENT test, following the Canadian Standard (Test Method LS-299) [25]. DENT test, which was used to determine the ductile failure resistance under horizontal tensile load application, at a specified temperature $\left(15^{\circ} \mathrm{C}\right)$. Initially, as per standard guidelines, a $15^{\circ} \mathrm{C}$ test temperature was considered based on the standard,_-but at this condition this inducedthe samples exhibited a premature brittle-failure (i.e., sample breakage). For this reason, the selection of and a higher testing temperature of $25^{\circ} \mathrm{C}$ was therefore selectedrequired in order to facilitate a more ductile material response. The fracture properties studied included: (1) The essential work of fracture $\left(W_{e}\right)$, (2) plastic work of fracture $\left(W_{p}\right)$, and (3) the approximated critical crack-tip opening displacement $(C T O D)$. These properties were calculated to study the resistance of the bitumen/NRMBs to ductile fracture. The DENT test was conducted after conditioning of the samples had been conditioned in a water bath (i.e., the specimens were submerged 25 _mm below water surface) at the target test temperature of $25^{\circ} \mathrm{C}$ for 180 minutes. The deformation load was applied at a controlled rate of $50 \mathrm{~mm} / \mathrm{min}$-deformation and it stopped when untilall the samples reached the ductile failure. During testing, data of the elongation length (in $\mathrm{mm}$ ), and force (in Newtons) was recorded and subsequently analysed to determine the fracture parameters (i.e., $W_{e}, W_{p}$ and $\left.C T O D\right)$ ).

The significance of the measuredCalculation of fracture properties for the comparison of the materials' fracture performance includerelate to: (1) the total work of fracture $\left(W_{t}\right)$, which refers to the area under the load versus 
load-line displacement curve, $\mathrm{kJ}$ (Equation 4); (2) the specific total work of fracture $\left(w_{t}\right)$, related to each replicate sample tested, $\mathrm{kJ} / \mathrm{m}^{2}$ (Equation 5); (3) the specific essential work of fracture $\left(w_{e}\right)$, the energy required to fracture or break the sample without plastic deformation away from the fracture zone, $\mathrm{kJ} / \mathrm{m}^{2}$; (4) the specific plastic work of fracture $\left(w_{p}\right)$, the non-essential work dissipated during the deformation of a volume of bitumen around the fracture zone, $\mathrm{MJ} / \mathrm{m}^{3}$; (5) the geometric constant of the plastic zone $(\beta)$, and (6) the critical tip opening displacement (CTOD), mm (Equation 6 and Equation 7).

$$
W_{t}=\int_{0}^{t_{f}} P \times d
$$

Equation 4

Where,

$P$ is the load in Newtons,

$d$ is the displacement in the test in $\mathrm{m}$,

$t_{f}$ is the time when the maximum stroke is reached or ductile failure, whichever is attained first.

$$
w_{t}=\frac{\left(\text { average } W_{t}\right)}{(B \times l)}
$$

Equation 5

Where,

$B$ is the sample thickness in $\mathrm{m}$, and

$l$ is the ligament length (the space between the notches) in $\mathrm{m}$.

$$
\operatorname{COTD}=\frac{w_{e}}{\sigma_{n}}
$$

Equation 6

Where,

$\sigma_{n}$ is the net section stress of specimen in $\mathrm{N} / \mathrm{m}^{2}$, calculated using

$$
\sigma_{n}=\frac{P_{\text {peak }}}{(B \times l)}
$$

Equation 7

Where,

$P_{\text {peak }}$ is the average peak load of the specimen tested with the smallest ligament length (i.e., the average maximum load for the $5 \mathrm{~mm}$ ligament specimens).

Determination of $w_{e}$ and $\beta w_{p}$ was is done either graphically by plotting $w_{t}$ for the three ligament lengths or mathematically using the least squares fitting method. $w_{e}$ refers to the specific essential work of fracture (i.e., $\mathrm{w}_{\mathrm{t}}$ value when $1=0.0$ ) and $\beta w_{p}$ is the slope of the best fit straight line (for $w_{t}=w_{e}+\beta w_{p} l$ ).

\subsubsection{Multiple Stress Creep Recovery (MSCR)}


The MSCR test was used to determine the permanent deformation susceptibility of the base bitumen and NRMBs. This test was conducted on unaged and RTFO-aged materials to study their elastic recovery properties. A DSR parallel-plate geometry with spindle diameter of $25 \mathrm{~mm}$ and $1 \mathrm{~mm}$ testing gap was used to undertake the test, using a Bohlin $\mathrm{CVO} \circledast$ equipment. Test temperature of $60^{\circ} \mathrm{C}$ was selected based upon typical ranges reported in literature for pavement surface temperature in Thailand $\left(65-68{ }^{\circ} \mathrm{C}\right.$ [26]; and 53-59 ${ }^{\circ} \mathrm{C}$ [27]). The test followed the AASHTO TP 70 Standard method [28]. In brief, the sample was loaded for 210 cycles of creeprecovery at two- $0.1 \mathrm{kPa}$ stress levels and 10 cycles for the $(0.1 \mathrm{kPa}$ and $-3.2 \mathrm{kPa}$ stress condition $)$. First, a 1 second creep load is applied and subsequently released for 9 seconds. Data was recorded by the DSR equipment and subsequently analysed in terms of the \% recovery (R-Value), the non-recoverable creep compliance $\left(J_{n r}\right)$, and the stress sensitivity parameter $\left(J_{n r-d i f f}\right)$. Equations as per standard were used to calculate the parameters for both stress conditions $(0.1 \mathrm{kPa}$ and $3.2 \mathrm{kPa})$. The $R$-value refers to the ability of bitumen to recover (i.e., dissipate stresses) after repeated loading and higher values reflect better material response in terms of permanent deformation. The $J_{n r}$ is an indicator of permanent deformation resistance that for higher values indicates a higher susceptibility to rutting distress of a given bitumen. The $J_{n r-\text { diff }}$ is used to distinguish the stress sensitivity of the bitumen due to the change of low stress $(0.1 \mathrm{kPa})$ to high stress $(3.2 \mathrm{kPa})$ conditions. Higher values of for-this parameter indicate higher sensitivity to the change in the loading stress to which the bitumen is subjected to under specific temperature conditions.

\subsection{Low-temperature Rheological Characterisation}


The low-temperature rheological properties for the bitumen/NRMBs were studied by means of the Bending Beam Rheometer (BBR) in accordance with the AASHTO T313-12 Standard [29]. In brief, the test method involved the application of a $980 \mathrm{mN}$ load to the beam specimen during 60 seconds of loading using the threepoint-bending approach. During the loading period, the low-temperature creep stiffness (S) and relaxation properties (m-values) were recorded and later analysed for assessing the temperature/dosage concentration effects and determination of critical low-temperature values $\left(T_{c}(S)\right.$ and $\left.T_{c}(m)\right)$ and the differential of these values, Delta Tc $-\left(\Delta T_{C}\right)$. The measured stiffness was calculated using the loading, deflection values and geometrical features of the beams manufactured by using the beam theory. The estimated stiffness was calculated as indieated-from a mathematical fitting of the data. The m-value refers to the slope of the relationship between the logarithmic of measured stiffness and is obtained at the logarithm of time for the total of 240 seconds of loading. Test temperatures included for the low-temperature characterisation included $-18{ }^{\circ} \mathrm{C}$ and $-24^{\circ} \mathrm{C}$.

Test temperatures were $-18^{\circ} \mathrm{C}$ and $-24^{\circ} \mathrm{C}$ and $\Delta T c$ values were calculated using Equation 8 . This parameter is a measure of the closeness of the critical low temperatures measured from the Stiffness and m-value with respect to their influence on the low temperature. Previous research has suggested this parameter is valid for more accurate prediction of field performance of bitumen (fatigue cracking response) as a result of its relation to bitumen ductility [30]. This research proposed two limits for $\Delta T c$ that refer to a cracking warning level and a limiting value of $-2.5{ }^{\circ} \mathrm{C}$ and $-5.0^{\circ} \mathrm{C}$. These criteria were incorporated in this research infor the discussion of results. The critical low-temperature values $\left(T_{c}(S)\right.$ and $\left.T_{c}(m)\right)$ were determined as per standard. From these values, the higher temperature is selected as the critical one for a given material [31].

$$
\Delta T c=T c(\text { Stiffness })-T c(m-\text { value })
$$

Equation 8

Where: $T c$ is the critical temperature for each of the BBR parameters $(S, m$-value $)$.

\subsection{Ageing Protocols}

To simulate ageing occurring during manufacturing and laying of bituminous mixtures, Short-Term Oven Ageing (STOA) and Long-Term Oven Ageing (LTOA) protocols were conducted on the base bitumen and NRMBs manufactured through the blending approach previously described. The STOA was carried out with the Rolling Thin Film Oven (RTFO) test [32] and LTOA with the Pressure Ageing Vessel (PAV) [33].

The effects of NR on NRMBs are analysed in terms of: (i) rheological characteristics at low-intermediate-high temperatures, and (ii) performance-related responses (fatigue performance, permanent deformation resistance 
and fracture properties). The effects of short- and long-term oven ageing on the rheology and performancerelated characteristics of NRMBs are also quantified.

\section{Rheological Changes Induced by NR}

\subsection{Intermediate-High Temperature Effects (Master Curves)}

The effects of NR in terms of the rheological changes induced to the base bitumen at the two-three NR eontents concentrations were assessed in terms of complex modulus $\left(G^{*}\right)$, and phase angle $(\delta)$ master curves as well asand the Black Space diagramsDiagrams. For the sake of brevity, oOnly the results of the unaged materials are shown taking into consideration that for the sake of brevity although the samesimilar observations were attained for the short-term (RTFO) and long-term (RTFO + PAV) ageing conditions in terms of $G^{*}$ and $\delta$ master curves and Black Space diagrams were found for the short term (RTFO) and long term (RTFO + PAV) ageing conditions. The rheological results in Figure 2 show that the effects of NR on the rheological parameters $G^{*}$ and $\delta$ are more pronounced at higher temperatures and lower loading frequencies as demonstrated in Figure 2a, and Figure 2b. These results indicate that NR produces NRMBs with an increased elastic response (i.e., lower phase angles) and increased stiffness (i.e., higher complex modulus) in comparison to the control bitumen, with this modification being more significant modification level reached for the for themaximum NR concentration $(-7 \%$ NRMB . At lower testing temperatures (i.e., higher loading frequencies) the complex modulus master curves show a decrease in the $G^{*}$ values for increasing NR dosages as compared to those of the control bitumen. While the change of $\delta$ with temperature and frequency is generally consistent with that of the $G^{*}$ master curves, the differences between the three binders are less evident at lower testing temperatures (higher loading frequencies).

The rheological data shown in the $\mathrm{G}^{*}$ and $\delta$ master curves is also plotted in the form of Black Space diagrams (Figure 2c) and used as an indicator of rheological changes induced by NR without the need to shift the data based on the time-temperature-superposition-principle (TTSP) [17]. The Black Space diagrams indicated a shift of the curves towards a more elastic behaviour (i.e., lower $\delta$ for both NRMBs) as the NR dosage increased, particularly for the higher $7 \%$ NR content. For the 3\% NR NRMB the level of modification is restricted to the high temperature (i.e., low frequency) domain with the rheological behaviour at low temperatures (i.e., high frequencies) being similar to that of the control bitumen. The Black diagrams also indicated that increased NR content produced a reduction in $G^{*}$ that substantiates the increased ductile response induced by NR on the binder rheology (discussed further for the low temperature BBR rheological results). Although not shown in Figure 2 for the sake of brevity, the effects of NR modification for the short- and long-term aged binders were 
consistent with those discussed for the unaged binders with the effect of ageing simply indicating an overall increase in $G^{*}$ and a reduction of $\delta$ values for all the binders as ageing increases. Overall, the comparison of the rheological parameters presented in Figure 2 substantiated the ability of NR to produce a more elastic response for the NRMBs as compared to that of the control bitumen. These results suggest an improvement of the permanent deformation resistance for increased NR content NRMBs due to their increased elastic response at high temperatures.
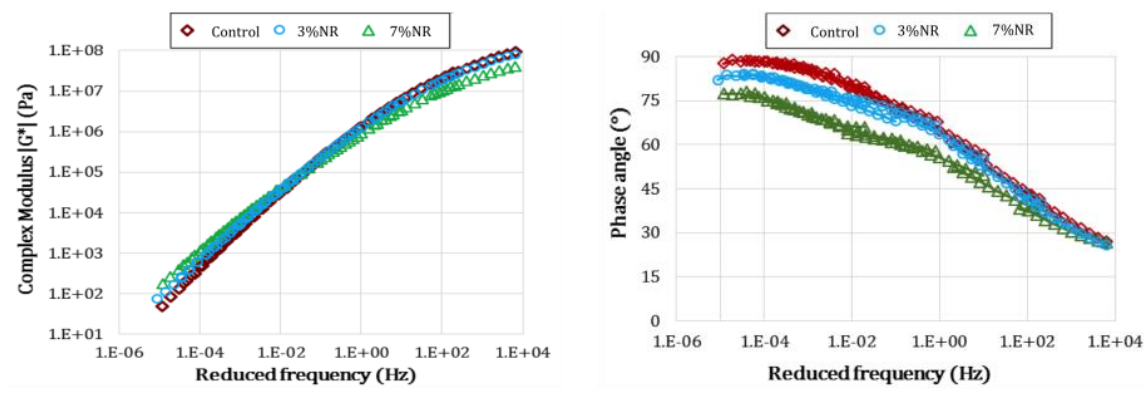

(a)

\section{Formatted: Not Highlight}

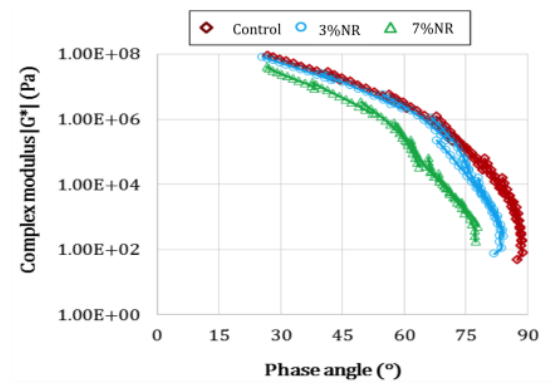

(c)

Figure 2. Comparison of the effects of NR on the rheological characteristics in terms of: (a) $G^{*}$ master curves, (b) $\delta$ master curves, and (c) Black-Space diagrams for unaged materials.

\subsection{Low-Temperature Effects and Thermal Cracking Susceptibility (BBR)}

The $S$ - and $m$-value comparisons for the two testing temperatures considered in this study are shown in Table 2 . From these values, the effect of NR on the low-temperature rheological behaviour showed a reduction of $S$ values (creep stiffness) as NR content increased from the control binder to $3 \%$ and $7 \%$ NR. However, the effect of NR on the relaxation properties (m-values) suggested a slower relaxation of the thermal stresses of the NRMBs considered in this study in contrast to that of the control bitumen. This means that high NR contents 
could induce brittle material response as a result of a reduced ability of these binders to stretch (i.e., lower ductility or loss in relaxation). However, the use of $m$-value does not represent a final indication of poor or good thermal cracking performance, as this parameter is associated with thermal stresses build up and the time required/available by the material to release these, which ultimately depends on the location and climate [34]. In consequence, the fact that the increase in NR content induced lower $m$-values does not imply that these NRMBs would have detrimental performance as this will depend on the weather conditions to which the pavement will be subjected to and it also depends on the $S$ values at low temperature, which were found to be lowered by the increase in NR content. As such, if one considers NR application in warmer climates, both $S$ and $m$-values do not represent a major risk as these locations are not subject to major thermal stresses with lowest temperatures being typically around $15^{\circ} \mathrm{C}$ at which block cracking or thermal cracking are not distresses of concern. For applications of NR in low-temperature regions, both BBR parameters and $\Delta T c$ need to be considered to find a balanced performance that satisfies the specifications imposed by the location/climate and the intrinsic material low-temperature response.

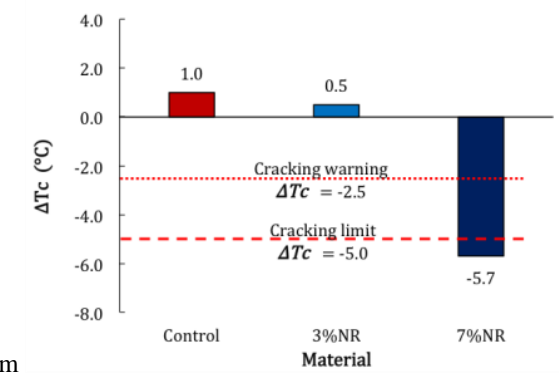

Figure 3 and Table 2 it is observed that the base bitumen and 3\% NRMB satisfied both cracking limits for lowtemperature for the $\Delta T c$ criterion, whereas the increase of NR to $7 \%$ did not comply and it is therefore expected to have high susceptibility to thermal cracking. This is probably a consequence of the effects of high-polymeric modification of bitumen with NR, which could lead to higher susceptibility of NRMBs to thermal cracking at high concentrations, as previously reported by $[35,36]$. In brief, from the rheological characterisation at lowtemperatures it was found that: (i) NR induced positive effects on the NRMBs in terms of a reduction of the creep stiffness $(S)$ at $-18{ }^{\circ} \mathrm{C}$ and $-24{ }^{\circ} \mathrm{C}$, which is indicative of lower thermal stresses induced by both NR contents considered; (ii) Conversely, the relaxation properties ( $m$-values) were negatively affected by increased NR content, which suggests a lower ability of the NRMBs to relax stresses (i.e., lower ductile response) in contrast to the control bitumen and; (iii) in terms of thermal cracking resistance, it was found that modification 
of control bitumen with NR content up to $3 \%$ would have satisfactory performance on the basis of the $\Delta T c$ failure criteria.

Table 2. Low-temperature properties (S, m-value) and critical temperatures and the corresponding differential temperature $\Delta T c$

\begin{tabular}{|c|c|c|c|c|c|c|c|}
\hline \multirow{3}{*}{ Material } & \multicolumn{2}{|c|}{ Stiffness } & \multicolumn{2}{|c|}{ m-value } & \multirow{3}{*}{$\begin{array}{c}\text { Critical } \\
\text { Temperature } \\
\text { Stiffness, S(c) } \\
\left({ }^{\circ} \mathrm{C}\right)\end{array}$} & \multirow{3}{*}{$\begin{array}{c}\text { Critical } \\
\text { Temperature } \\
\text { m-value, } \\
\text { m(c) }\left({ }^{\circ} \mathrm{C}\right)\end{array}$} & \multirow{3}{*}{$\Delta \operatorname{Tc}\left({ }^{\circ} \mathrm{C}\right)$} \\
\hline & \multicolumn{2}{|c|}{ (MPa) } & & & & & \\
\hline & $-18^{\circ} \mathrm{C}$ & $-24^{\circ} \mathrm{C}$ & $-18^{\circ} \mathrm{C}$ & $-24^{\circ} \mathrm{C}$ & & & \\
\hline Control & 537 & 854 & 0.242 & 0.188 & -10.497 & -11.500 & 1.003 \\
\hline Control+3\% NR & 504 & 790 & 0.235 & 0.174 & -11.103 & -11.607 & 0.504 \\
\hline Control+7\% NR & 462 & 747 & 0.206 & 0.155 & -12.608 & -6.941 & -5.667 \\
\hline
\end{tabular}

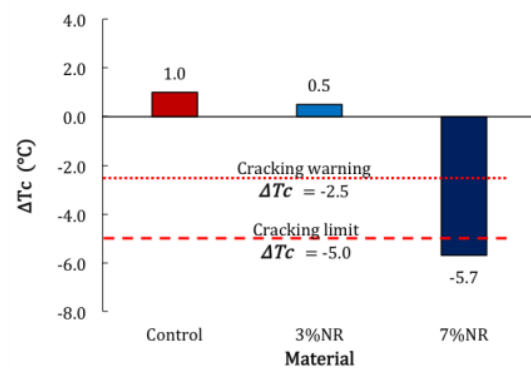

Figure 3. Comparison of the thermal cracking susceptibility for control bitumen and NRMB in terms of $\Delta T c$ values.

\section{Performance-Related Effects of NR}

\subsection{Effects of NR on Fatigue Performance}

The characteristic VECD coefficients for the base bitumen (control) and NRMBs are presented in Table 3. The trends observed in the VECD coefficients indicate both the effects of temperature and NR content, which induced differences in the damage response that was captured via the $C_{0}, C_{1}$ and $C_{2}$ coefficients. The results show an increase of $C_{1}$ was induced by the increase in NR content, whereas $C_{2}$ decreased for increased NR content. These differences substantiate the fact that $7 \%$ NRMB presents a higher reduction in initial $\left|G^{*}\right|$ at low damage intensity levels, whereas the reduction is less prominent for higher levels of damage. Furthermore, this 
indicates that both NR contents induced positive effects on the damage resistance (captured by lower decrease in the initial $\left|G^{*}\right|$ in comparison to the base bitumen) that turn into higher fatigue cracking resistance as further discussed in this section. Overall, the assessment of the VECD damage coefficients indicated that the largest $C_{0}, C_{1}$ and smallest $C_{2}$ values relate to the NRMB with $7 \% \mathrm{NR}$. The temperature effects of $10^{\circ} \mathrm{C}$ difference on the fatigue performance were also captured as reflected by the changes in the VECD coefficients, the damage intensity curves and the fatigue life curves. The results show that the higher $25{ }^{\circ} \mathrm{C}$ test and analysis produced significantly lower $C_{0}$ and $C_{1}$ values whereas $C_{2}$ remained almost unaltered. The damage intensity curves substantiated significant reduction in the stiffness of the materials as a result of the temperature increase and the fatigue life reflected this effect in higher $N f$ for the higher testing temperature. Overall, it was found that the addition of NR produced NRMBs with higher damage resistance in contrast to the base bitumen.

Table 3. VECD coefficients for control and NRMB at $15^{\circ} \mathrm{C}$ and $25^{\circ} \mathrm{C}$.

\begin{tabular}{ccccccc}
\hline \multirow{2}{*}{ Material } & \multicolumn{7}{c}{$\mathbf{1 5}^{\circ} \mathbf{C}$} & & $\mathbf{2 5}^{\circ} \mathbf{C}$ & \\
\cline { 2 - 7 } & $\mathbf{C}_{\mathbf{0}}$ (MPa) & $\mathbf{C}_{\mathbf{1}}$ (MPa) & $\mathbf{C}_{\mathbf{2}}$ & $\mathbf{C}_{\mathbf{0}}$ (MPa) & $\mathbf{C}_{\mathbf{1}}$ (MPa) & $\mathbf{C}_{\mathbf{2}}$ \\
\hline Control & 44.51 & 0.092 & 0.434 & 13.2 & 0.084 & 0.424 \\
\hline Control + 3\% NR & 44.06 & 0.117 & 0.381 & 12.93 & 0.104 & 0.383 \\
\hline Control + 7\% NR & 46.52 & 0.149 & 0.344 & 16.81 & 0.179 & 0.299 \\
\hline
\end{tabular}

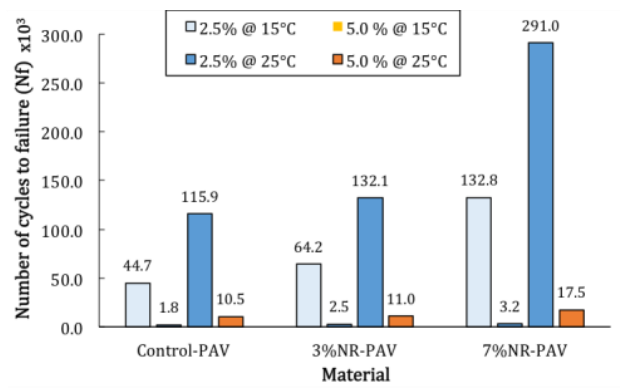

Figure 4. Comparison of fatigue lives for PAV-aged materials at $2.5 \%$ and $5 \%$ strain at $15{ }^{\circ} \mathrm{C}$ and $25{ }^{\circ} \mathrm{C}$.

A comparison of the fatigue lives (number of cycles to reach failure, $N_{f}$ ) are shown in Figure 4. As observed previously, temperature and NR content effects were identified. For both temperatures, $N_{f}$ increased as a function of the NR content, which was consistent for both the low and high strains considered $(\gamma=2.5 \%$ and $\gamma=$ $5.0 \%$ ). At $15^{\circ} \mathrm{C}$ testing temperature and $2.5 \%$ strain, a $44 \%$ increase in fatigue life was found for $3 \% \mathrm{NR}$ and a $197 \%$ increase for $7 \% \mathrm{NR}$ in contrast to that of control bitumen. At $15{ }^{\circ} \mathrm{C}$ and $5 \%$ strain, this increase was less prominent $\left(36 \%\right.$ for $3 \% \mathrm{NR}$ and $76 \%$ for $7 \% \mathrm{NR}$ ). The effects of increasing the test temperature by $10^{\circ} \mathrm{C}$ also 
produced differences in the fatigue lives, which were reflected by higher $N_{f}$ values for the $25^{\circ} \mathrm{C}$ testing temperature for all materials and strains considered. From the macroscopic perspective (i.e., visual inspection of the samples after testing), the fatigue of all the materials exhibited a failure plane that followed a factory-roof morphology and a circumferential torsional failure (i.e., growing from the inside to the outside of the bitumen/NRMBs specimens), which is consistent with previous findings by [22] and substantiates an adequate bitumen/plate bonding during testing.

\subsection{Effects of NR on Permanent Deformation Resistance}

The effects of NR on permanent deformation resistance is presented and discussed in this section in terms of the evolution of accumulated strain over time, the effects of ageing, and the comparison of rutting parameters (nonrecoverable creep compliance $J_{n r}$, and-percent recovery $R$-value, stress sensitivity parameter $J_{n r \text {-diff }}$.

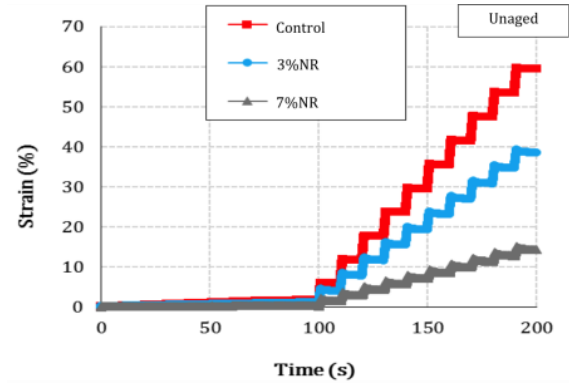

(a)

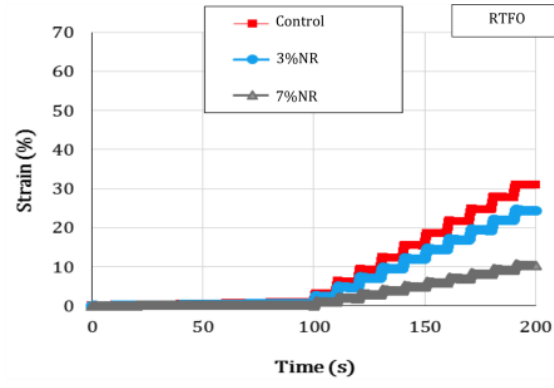

(b)

Figure 5. Strain versus time for (a) unaged bitumen, and (b) RTFO aged bitumen, at $60{ }^{\circ} \mathrm{C}$.

The strain and accumulated strain versus time presented in Figure 5 and Figure 6, respectively, show a positive effect of NR on increased resistance to permanent deformation in contrast to the base bitumen. In Figure 5, the initial 100 seconds refer to the $0.1 \mathrm{kPa}$ stress condition and the subsequent steps of cumulative strain are due to the impact of a much higher stress regime $(3.2 \mathrm{kPa})$, which is easily observed and captures the effect of NR modification of the base bitumen. The higher NR contents induced a reduction in the accumulated strain for both NRMBs with 3\% NR and 7\% NR, which was observed for both unaged and STOA conditions and for both stress levels considered $(0.1 \mathrm{kPa}$ and $3.2 \mathrm{kPa})$. This reduction in accumulated strain highlights a positive influence exerted by NR on bitumen modification in terms of a reducedreduced permanent deformation susceptibility of the NRMBs in comparison to that of control bitumen (Figure 6). 


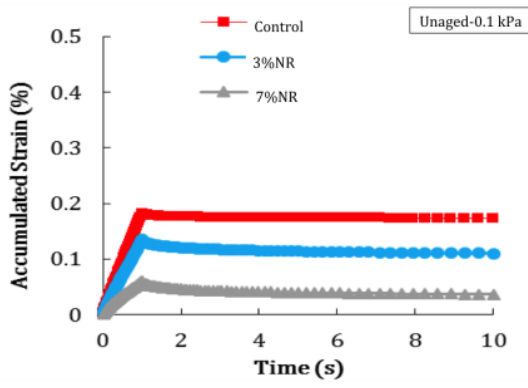

(a)

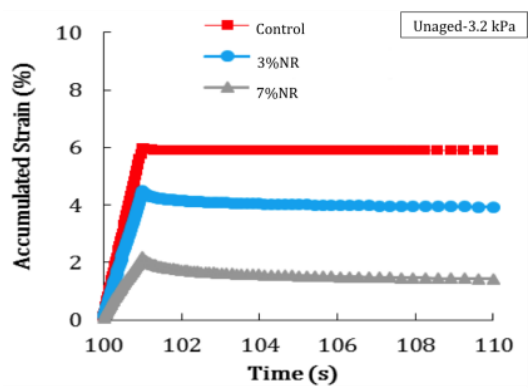

(c)

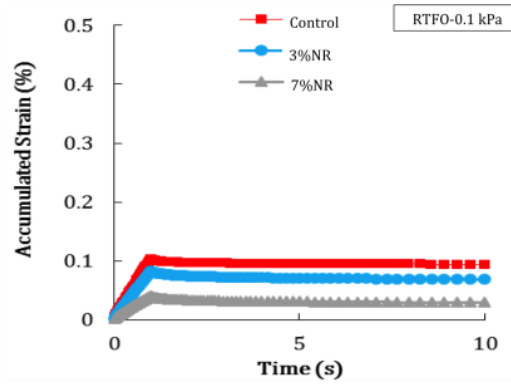

(b)

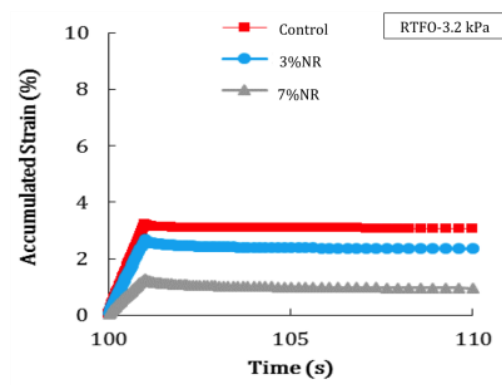

(d)

Figure 6. Effects of stress on the accumulated strain for unaged, and RTFO-aged bitumen, at $60{ }^{\circ} \mathrm{C}$. (a) Unaged at $0.1 \mathrm{kPa}$, (b) RTFO at $0.1 \mathrm{kPa}$, (c) Unaged at $3.2 \mathrm{kPa}$, and (d) RTFO at $3.2 \mathrm{kPa}$.

The effects of NR on the resistance to permanent deformation, assessed in terms of the average percentage recovery $(R$-value $)$ and non-recoverable creep compliance $\left(J_{n r}\right)$, indicated that increasing NR content enhanced this material response as compared to that of the base bitumen. Consistently for both unaged and RTFO-aged materials and at both stress levels, it was observed that $J_{n r}$ decreased and the $R$-values increased as the NR content increased. Figure 7 show the effects of STOA ageing, NR content and stress level on the nonrecoverable creep compliance $\left(J_{n r}\right)$. The change from unaged to STOA produced stiffer materials as captured by the lower $J_{n r}$ values for both control bitumen and NRMBs at $3 \% \mathrm{NR}$ and $7 \% \mathrm{NR}$ content. The increase in stress level from $0.1 \mathrm{kPa}$ to $3.2 \mathrm{kPa}$ increased the value of $J_{n r}$ by approximately $10 \%$. Furthermore, the effect of increased NR content showed a clear trend of reduction in the $J_{n r}$ values for both stress levels and ageing conditions, which substantiates the positive influence of NR on this material response.

These parameters provide evidence of the positive effects of NR on the permanent deformation resistance of the modified control bitumen. Similarly, the effects of ageing were also demonstrated based on the $J_{n r}$ and $R$-values shown in Figure 8. Similar to the effect seen for unmodified binders, subjecting the NRMBs to STOA improves 
the rutting resistance of the modified binders meaning that positive observations in terms of permanent deformation resistance held true for both NR content and ageing condition.

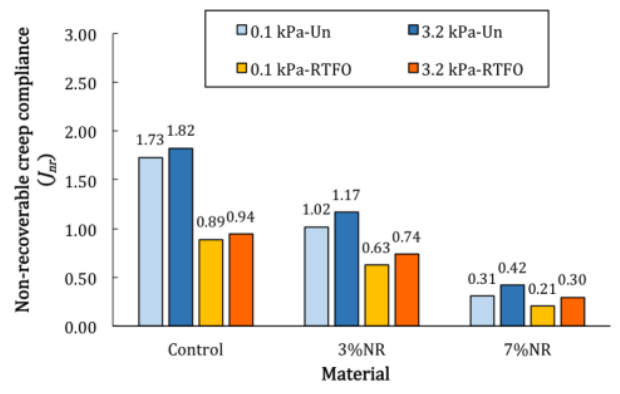

Figure 7. Comparison of the effect of NR and ageing on the permanent deformation, presented in terms of nonrecoverable creep compliance $\left(J_{n r}\right)$ for unaged materials, and RTFO aged materials.

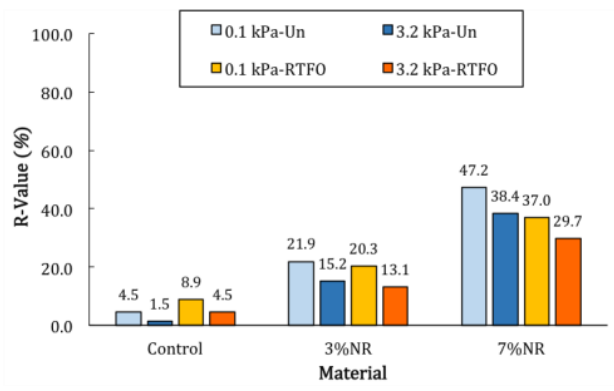

Figure 8. Comparison of the effect of NR and ageing on the permanent deformation, presented in terms of average percentage recovery ( $R$-value $)$ for unaged materials, and RTFO aged materials.

The $J_{n r}$ results are in agreement with those observed for the R-values with higher R-values indicating a higher resistance to permanent deformation. As such, the combined effects of ageing, stress level and NR content are presented in Figure 8, where it becomes clear that ageing and NR content increased the permanent deformation resistance of the binders. Furthermore, as it would be expected for bituminous materials, the increase of stress level induced a substantial decrease of the R-values, indicating the stress sensitivity of the materials with increased NR content. The reduction in the percent recovery $(\% \mathrm{R})$ is explained by the possible damaging of the NR crosslink structure (i.e., polymer network stability) induced by this short-terms ageing protocol, which inevitably affects the permanent deformation response of the NRMBs at both concentrations studied. Under this oxidative condition, the hardened bitumen phase is responsible for the most part of the rheological response. 
Previous research found similar results of dropping recovery values when polymer-modified bitumen blends were subjected to artificial ageing cycles in both RTFO and PAV [35, 36]. Furthermore, the $\boldsymbol{J}_{n r-\text { diff }}$ values shown considered. However, this is a common effect of high polymer modification of bitumen, which has been

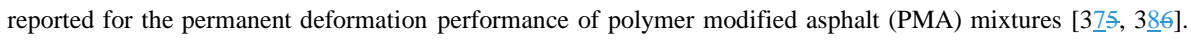
From these results, however, it is surprising that short-term ageing of the 7\% NRMB did have a reduction of the stress sensitivity, which could result from possible errors in rheological data captured by DSR due to the high stiffness gain induced by the high-NR content in contrast to $3 \% \mathrm{NR}$ or the base bitumen, or it might be related to variability between replicate materials during production of the DSR samples. Therefore, from $J_{n r-d i f f}$, it might be deduced that higher NR contents led to detrimental effects on the stress sensitivity for both ageing conditions, which needs to be considered for optimum dosage selection in conjunction with other performance-related characterisations to attain a balanced performance for a given NR content. However, based on standard recommendations [397], all the materials fulfilled the criteria as they were all below $75 \%$, which suggests satisfactory stress sensitivity for both NR contents.

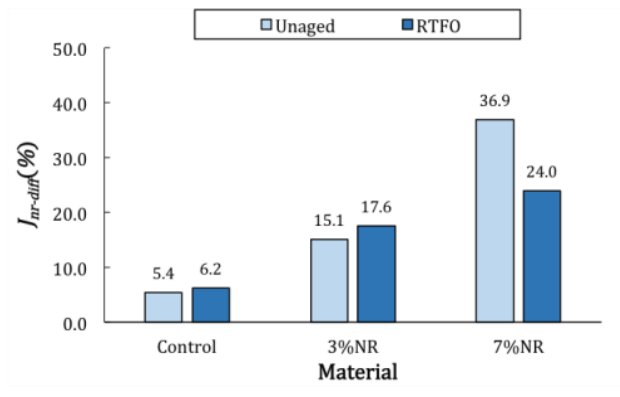

Figure 9. Stress sensitivity for unaged and RTFO-aged materials.

\subsection{Influence of NR on the fracture characteristics}

The specific total work of fracture $(W t)$, essential work of failure $(W e)$, plastic work of failure $\left(\beta w_{p}\right)$, and critical crack opening displacement $(C T O D)$ are presented in this section to discuss the effects of NR on the fracture properties of the modified binders. Prior to the fracture parameters, the plane-stress/plane-strain mixed mode of testing was verified through the correlation between net section stress and ligament length, which indicated a decrease in the net section stress as the ligament length increased. The Wt values for the base bitumen and NRMB at $3 \%$ and $7 \%$ are shown in Figure 10 where a higher slope can be observed for $7 \%$ NR content in 
contrast to the base bitumen and 3\% NR. These results indicate an improved yielding capacity and increase in the fracture energy for NRMB with $7 \%$ NR content, whereas the $3 \%$ NR content did not produce the same extent of influence on the fracture energy and therefore its yielding capacity is reduced [38]. As observed in Figure 10, the essential work of fracture for 3\% NR content exceeded that of the base bitumen, whereas $7 \%$ NR content provided the lowest We values. This indicates that the 3\% NR content enhanced the resistance to fracture due to a higher ductile strain tolerance in contrast to those of the base bitumen and $7 \%$ NR. This finding is consistent with previous research $[39,40]$. The former study showed a positive correlation between higher $W t$ values and $\beta w_{p}$ with enhanced fatigue cracking of real pavement sections due to enhanced ductile strain tolerance. The latter study proved that inclusion of RAP to polymer modified bitumen led to unsatisfactory fracture properties, which included decreased $\mathrm{Wt}$ and $\beta w_{p}$ values.

The plastic work of failure ( $\beta w_{p}$ values related to the slopes of the curves) is shown in Figure 10a and this parameter was used as an indicator of the fatigue cracking resistance of the base bitumen and NRMBs based on recent literature [4042]. It can be observed that for the 7\% NR (0.7726), the $W_{t}$ increases at a higher rate in contrast to that of the base bitumen (0.5112) and 3\% NR (0.2765), respectively, which would suggest $7 \%$ as the most adequate NR concentration. However, other fracture properties are also required for confirming this observation, thus $C T O D$ and $W_{e}$ were also determined. The CTOD values are in agreement with those of $W_{e}$ (Figure 10b), which substantiates the fact that NR contents above 3\% might lead to deleterious effects on the fracture resistance for the material combinations studied in this paper. This could be the result of NR concentrations reaching a maximum level of yielding capacity and strain tolerance that is below the $7 \%$ studied in this paper. This might be due to the physicochemical reaction of higher NR content with the base bitumen due to the higher concentration of polymeric chains in the bitumen matrix that are able to alter the ductile response under high strain concentrations at the testing temperatures considered. SimilarlyFurthermore, the data presented in Table 4 is consistent with the previous discussion of the fracture parameters in terms of the failure deformation and peak load. These results show that a NR content of 3\% leads to improved fracture resistance as a consequence of the lower peak loads and increased deformation. The $3 \%$ NR content therefore induced better fracture properties for the materials studied, whereas $7 \%$ NR exhibited detrimental effects on the fracture of NRMBs.

Furthermore, the results observed for the maximum concentration of NR in the NRMBs might be associated by the detrimental side effects produced by the artificial ageing regimes (i.e., RTFO and PAV) that are required 
prior testing for DENT. More precisely, as discussed before, the polymer network or cross-link of the NR molecules seems to be disintegrated by the short-and long-term ageing, which results in stress concentration in the bitumen matrix. Previous research on fracture response of SBS-modified bitumen through DENT testing found that high polymer concentrations (i.e. higher than $2 \%$ ) tend to have poorer fracture performance in comparison to reasonably low contents of modifiers. In fact, the use of WMA additives such as Fischer-Tropsch (FT), chemical surfactants (CS) and water-based (WB) have the ability to modify the fracture response, which tends to be concentration-dependent and showed improved fracture response at $2 \%$ concentration for CS WMAadditive type, but this response was opposite for the FT and WB types with the only exception of $6 \%$ WB concentration [43]. Additional research by [44] substantiated a detrimental ductile response of high-polymer modified bitumens with SBS (i.e., 3-5\% concentration by weight of base bitumen). In fact, it was found that both in unaged and PAV-aged conditions, the CTOD values for the SBS-modified samples had lower ductile performance (i..e, lower CTOD values), with one single exception to this trends for a SBS-blend (A5), which had the same CTOD value, measured at deformation rate of $50 \mathrm{~mm} / \mathrm{min}$, as the base bitumen after long-term ageing protocol. Additional research on PMB-bitumen modification through various concentrations of RAP binder (i.e., $0 \%, 15 \%, 25 \%$, and $40 \%$ ) indicated that the higher concentrations of this bitumen modified negatively affect the intermediate temperature response in terms of the ductile properties measured through DENT and elastic recovery tests [45]. Conversely, [46] found that for low-SBS polymer concentrations the fracture performance after PAV-ageing seems comparable and at some instances superior to that of base bitumen for concentrations ranging from $1.2 \%$ to $1.8 \%$ by weight of base bitumen. It was also found that the superior response at RTFO ageing conditions is not equaled by that of PAV-aged materials, indicating a detrimental effect of artificial ageing on the fracture response for these material combinations. 


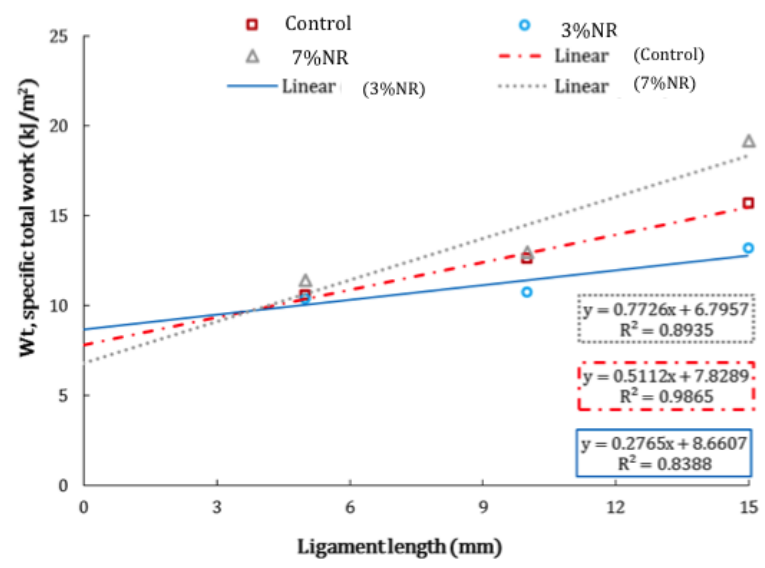

(a)

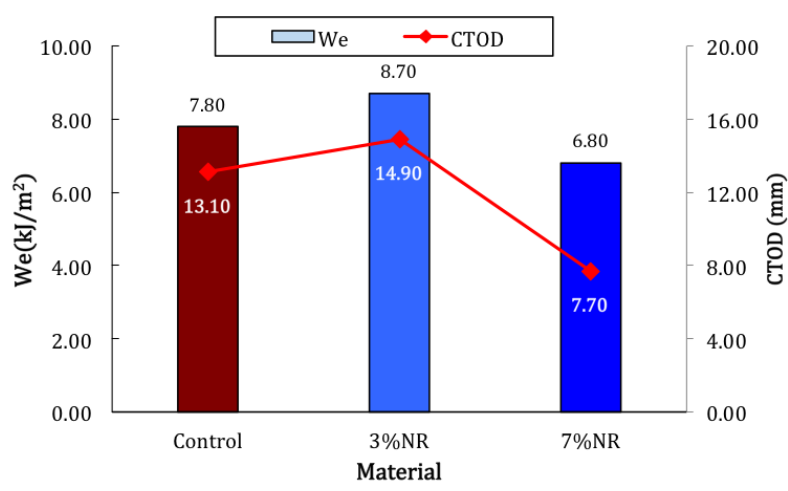

(b)

Figure 10. (a) The specific total work of fracture $\left(W_{t}\right)$ and plastic work of failure $\left(\beta w_{p}\right)$, (b) essential work of failure $\left(W_{e}\right)$, and critical crack opening displacement (CTOD) for neat bitumen and NRMBs. 
Table 4. Summary of peak load and deformation to failure for neat binder and NRMBs.

\begin{tabular}{|c|c|c|c|c|c|c|}
\hline \multirow[t]{3}{*}{ Material } & \multicolumn{6}{|c|}{ DENT insert length (mm) } \\
\hline & \multicolumn{2}{|r|}{5} & \multicolumn{2}{|c|}{10} & \multicolumn{2}{|c|}{15} \\
\hline & $\begin{array}{c}\text { Peak } \\
\operatorname{Load}(\mathbf{N})\end{array}$ & $\begin{array}{c}\text { Failure } \\
\text { Deformation } \\
(\mathbf{m m})\end{array}$ & $\begin{array}{c}\text { Peak Load } \\
\text { (N) }\end{array}$ & $\begin{array}{c}\text { Failure } \\
\text { Deformation } \\
(\mathbf{m m})\end{array}$ & $\begin{array}{c}\text { Peak Load } \\
\text { (N) }\end{array}$ & $\begin{array}{c}\text { Failure } \\
\text { Deformation } \\
\text { (mm) }\end{array}$ \\
\hline Control & 30 & 34.8 & 40 & 67.2 & 46 & 118 \\
\hline Control $+3 \%$ NR & 29 & 47.2 & 37 & 80.6 & 42 & 134 \\
\hline Control + 7\% NR & 44 & 32 & 57 & 56.2 & 66 & 94 \\
\hline
\end{tabular}

\section{Conclusions}

The laboratory investigation described in thise paper assessed the effects of NR on the rheological and performance-related characteristics of modified bitumens (NRMB-). - This was achieved through a comprehensive laboratory programme that incorporatedincorporating the evaluation of NR effects on bitumen rheology and the evaluation of fatigue cracking, thermal cracking, permanent deformation and fracture properties of the NR modified binders NRMB. Two NRMB blends were manufactured with $3 \%$ and $7 \%$ NR by mass of the final modified-binder using a 40/60-penetration grade base bitumen (control). The test methods included: (1) Dynamic Shear Rheometer (DSR) master curves and Black Space diagrams together with Bending Beam Rheometer (BBR) tests for rheological assessment over a wide temperature range; (2) Linear Amplitude Sweep (LAS) tests for assessing fatigue at intermediate temperatures; (3) Multiple Stress Creep Recovery (MSCR) tests for permanent deformation at high temperature; and (4) the evaluation of fracture properties at intermediate temperatures using the Double Edged-Notched Test (DENT) test. Based on the experimental results and analysis, the following main conclusions can be drawn:

1) The effects of NR on the bitumen rheology produced changes in the rheological parameters $\left(G^{*}\right.$ and $\left.\delta\right)$ that were captured via the master curves and Black Diagrams. It was observed that increased NR content produced significant increase of the stiffness of NRMBs (higher $G^{*}$ ) that was particularly pronounced at high testing temperatures. Similarly, the decrease of $\delta$ values are consistent with the results of $G^{*}$ and the Black Diagrams showed a shift of the NRMBs curves towards a zone related to more elastic response in 
2) The rheological characterisation at low-temperatures found that: (i) NR induced positive effects on the NRMBs in terms of a reduction of creep stiffness $(S)$ at $-18^{\circ} \mathrm{C}$ and $-24^{\circ} \mathrm{C}$, which is indicative of lower thermal stresses being induced in the NRMBs; (ii) The relaxation properties ( $m$-values) were also affected by increased NR content although the $m$-values showed a lower ability of the NRMBs to relax stresses in contrast to the control bitumen and; (iii) In terms of thermal cracking resistance, it was found that a NR content of $3 \%$ would have satisfactory performance on the basis of the $\Delta T c$ failure criterion. From a practical point of view, these results imply some restricted use of NR in cold regions or those with significant day/night temperature gradients and supports its use in tropical regions.

3) The fatigue performance of the NRMB blends assessed by means of the LAS testing indicated that NR increased the fatigue life of the base bitumen by a significant extent at the intermediate temperatures considered $\left(15^{\circ} \mathrm{C}\right.$ and $\left.25^{\circ} \mathrm{C}\right)$. This impact on fatigue life was consistent for both strain levels $(\gamma=2.5 \%$ for thin pavement structures and $\gamma=5.0 \%$ for thick pavement structures) but it was more prominent at the lower strain level. In general, the results showed a higher number of cycles to reach failure ( $N f$ ) for $7 \%$ NRMB as compared to those of control bitumen and 3\% NRMB. These findings were consistent for the temperatures considered, which suggests positive effects of NR on bitumen modification with regard to fatigue cracking.

4) Positive effects of NR on the permanent deformation resistance were observed indicating an increased resistance for both NR contents considered. The maximum resistance was reached for the $7 \% \mathrm{NR}$ content as it related to the highest $R$-values and lowest $J_{n r}$ parameter for all combinations studied. These results substantiated the positive influence of NR on the rutting response for the NRMBs when compared to that of base bitumen for both unaged and RTFO-aged materials. However, some detrimental effects on the polymer structure (crosslink of the NR molecules) of the short-term ageing regime did likely occur as observed by slightly reduced R-values for the RTFO-aged materials. The stress effects on the NRMBs resistance to rutting indicated that the improvement of this material response was predominant for higher stresses (3.2 $\mathrm{kPa})$ in contrast to the lower stress considered $(0.1 \mathrm{kPa})$. Nevertheless, the stress sensitivity $\left(J_{n r-d i f f}\right)$ increased with NR addition to the base bitumen, reaching a maximum for $3 \%$ NR content for both ageing 
conditions, which is expected as a result of high-content polymeric modification of bitumen, such as that provided by Styrene-Butadiene-Styrene (SBS) in polymer modified mixtures (PMA)

5) The NRMBs exhibited a limited fracture response as observed with the DENT test results in terms of the fracture properties of $W_{t}, W_{e}, \beta w_{p}$, and $C T O D$. In practical terms, based on the material combinations considered, these results suggest that NR content should not exceed $3 \%$ when attempting to minimize fatigue cracking and improve fracture performance at the micro scale. Similarly, other NR dosages should be explored with different base bitumen types than those included in this investigation for further validation of fracture properties.

Overall, the evidence obtained through the experimental programme and materials tested substantiates some performance-related benefits of NR and its suitability for applications in warmer countries, such as Thailand or those encountered in South East Asia where NR is produced and widely available, for which where the rutting distress and fatigue of fatigue and permanent deformation of pavements represents the major challenges for mixture design, performance and durability. Furthermore, a possible increase in the current limits of NR use for road infrastructure is envisioned as a practical application of this research study, when complemented with additional future studies. Similarly, these results encourage use of NR in other countries aiming at promoting sustainable road infrastructure

$\underline{\text { Some recommendations for future work include: }}$

- Although storage stability of the samples has not been studied by this research work, previous work by [47] substantiated that NR contents of up to $6 \%$ exhibit stable performance for use at high temperatures. Furthermore, [48] demonstrated with factual evidence that contents up to $9 \%$ can have satisfactory storage stability and indicated that this property is largely dependent on the NR concentration. Similar findings were reported by [49], who reported satisfactory storage stability for blends subjected to conditioning for 72 hours at $163^{\circ} \mathrm{C}$. Therefore, future studies might add value to the characterization of NRMB by incorporating the storage stability results.

- In terms of the complexity of bitumen modification through NR in comparison to other polymers, our experience and that reported by previous research indicates $[50,51]$, the following: Overall, it is harder to mix NR latex than other polymers because of its liquid nature in contrast to others being capsules or grinded materials (solid-like). Furthermore, the fact that NRL contains "water" in the latex, and have high ammonia content makes it hard to produce blending due to the physical effects (i.e., frothing and foaming), in addition to the strong smell produced by the ammonia. For these reasons, the liquid NRL

Formatted: Justified

Formatted: Justified, Bulleted + Level: $1+$ Aligned at: $0.25^{\prime \prime}+$ Indent at: $0.5^{\prime \prime}$

Formatted: Font: $10 \mathrm{pt}$, Font color: Auto, English (United States)

Formatted: List Paragraph, Bulleted + Level: $1+$ Aligned at: $0.25^{\prime \prime}+$ Indent at: $0.5^{\prime \prime}$

Formatted: Font: 10 pt, Font color: Auto, English (United States) 
is gradually added to the base bitumen at small portions, which allows for reducing the air bubbles and evaporation. This is aided by manual stirring to minimize the foaming of the rubber to reach the top head of the mixing machine. Certainly, this procedure means more time consumption than other polymers but it allows for homogeneous blend if carried out cautiously by future researchers.

Formatted: Font color: Auto, English (United States)

Formatted: List Paragraph

Formatted: English (United States)

\section{Acknowledgements}

Jarurat Witinapanit expresses deep gratitude for the sponsorship offered by the Thailand government to conduct M.Sc. studies at the University of Nottingham. Similarly, Juan S. Carvajal-Munoz acknowledges the valuable support provided by the Universidad del Norte (CCBUNDDA/12/2016), and Colciencias-Colfuturo (Colombia) (728 National Call, 2015) to conduct Ph.D. studies at the University of Nottingham, United Kingdom.

\section{References}

[1] Rubber Journal Asia. (2017). Malaysia still evaluating feasibility of rubberised roads in pilot projects. [online] Available at: http://rubberjournalasia.com/malaysia-still-evaluating-feasibility-of-rubberised-roadsin-pilot-projects/ [Accessed 20 Feb. 2019].

[2] Reuters. (2014). Malaysia plans rubber roads as producers struggle to lift prices. [online] Available at: https://www.reuters.com/article/asia-rubber-anrpc-idUSL3N0S81ZH20141013 [Accessed 20 Feb. 2019].

[3] Gawel, I., Stepkowski, R. and Czechowski, F. (2006). Molecular Interactions between Rubber and Asphalt. Industrial \& Engineering Chemistry Research, 45(9), pp.3044-3049.

[4] Celauro, B., Celauro, C., Lo Presti, D. and Bevilacqua, A. (2012). Definition of a laboratory optimization protocol for road bitumen improved with recycled tire rubber. Construction and Building Materials, 37, pp.562-572.

[5] Lo Presti, D. (2013). Recycled Tyre Rubber Modified Bitumens for road asphalt mixtures: A literature review. Construction and Building Materials, 49, pp.863-881.

[6] Subhy, A., Lo Presti, D. and Airey, G. (2015). An investigation on using pre-treated tyre rubber as a replacement of synthetic polymers for bitumen modification. Road Materials and Pavement Design, 16(sup1), pp.245-264.

[7] Heitzman, M. (1992). Design and construction of asphalt paving materials with crumb rubber modifier. Transportation Research Record, 1339.

[8] Yildirim, Y. (2007). Polymer modified asphalt binders. Construction and Building Materials, 21(1), pp.6672.

[9] Mashaan, N., Ali, A., Koting, S. and Karim, M. (2013). Performance Evaluation of Crumb Rubber Modified Stone Mastic Asphalt Pavement in Malaysia. Advances in Materials Science and Engineering, 2013, pp.1-8. 
[10] Takallou, H. and Hicks, R. (1988). Development of improved mix and construction guidelines for rubber modified asphalt pavements. [Washington, D.C.]: [Transportation Research Board].

[11] Fontes, L., Trichês, G., Pais, J. and Pereira, P. (2010). Evaluating permanent deformation in asphalt rubber mixtures. Construction and Building Materials, 24(7), pp.1193-1200.

[12] Pasquini, E., Canestrari, F., Cardone, F. and Santagata, F. (2011). Performance evaluation of gap graded Asphalt Rubber mixtures. Construction and Building Materials, 25(4), pp.2014-2022.

[13] Wang, H., Dang, Z., Li, L. and You, Z. (2013). Analysis on fatigue crack growth laws for crumb rubber modified (CRM) asphalt mixture. Construction and Building Materials, 47, pp.1342-1349.

[14] Kaloush, K. (2014). Asphalt rubber: Performance tests and pavement design issues. Construction and Building Materials, 67, pp.258-264.

[15] Al-Mansob, R., Ismail, A., Alduri, A., Azhari, C., Karim, M. and Yusoff, N. (2014). Physical and rheological properties of epoxidized natural rubber modified bitumens. Construction and Building Materials, 63, pp.242-248.

[16] Al-Mansob, R., Ismail, A., Yusoff, N., Albrka, S., Azhari, C. and Karim, M. (2016). Rheological characteristics of unaged and aged epoxidised natural rubber modified asphalt. Construction and Building Materials, 102, pp.190-199.

[17] Airey, G. (2002). Use of Black Diagrams to Identify Inconsistencies in Rheological Data. Road Materials and Pavement Design, 3(4), pp.403-424.

[18] Bahia, H., and Teymourpour, P. (2014). Linear Amplitude Sweep Test: Binder Grading Specification and Field Validation. Asphalt Binder Expert Task Group Meeting, Baton Rouge, LA, September 16, 2014.

[19] AASHTO TP101. (2014). Estimating damage tolerance of asphalt binders using the linear amplitude sweep.

[20] Hintz, C., Velasquez, R., Johnson, C. and Bahia, H. (2011). Modification and Validation of Linear Amplitude Sweep Test for Binder Fatigue Specification. Transportation Research Record: Journal of the Transportation Research Board, 2207(1), pp.99-106.

[21] Ding, H., Rahman, A., Li, Q. and Qiu, Y. (2017). Advanced mechanical characterization of asphalt mastics containing tourmaline modifier. Construction and Building Materials, 150, pp.520-528.

[22] Nuñez, J., Leonel, E. and Faxina, A. (2016). Fatigue characteristics of modified asphalt binders using fracture mechanics. Engineering Fracture Mechanics, 154, pp.1-11.

[23] Lytton, R. L., Chen, C. W., \& Little, D. N. (2001). Microdamage healing in asphalt and asphalt concrete, volume IV: A viscoelastic continuum damage fatigue model of asphalt concrete with microdamage healing (No. FHWA-RD-98-144).

[24] Bahia, H., Tabatabaee, H., Mandal, T. and Faheem, A. (2013). Field evaluation of Wisconsin modified binder selection guidelines - phase II. Madison: Wisconsin Department of Transportation.

[25] Test Method LS-299. (2001). Method of test for the determination of asphalt cement's resistance to ductile failure using Double Edge Notched Tension Test (DENT). Ministry of Transportation, Ontario, Canada.

[26] Jitsangiam, P., Chindaprasirt, P. and Nikraz, H. (2013). An evaluation of the suitability of SUPERPAVE and Marshall asphalt mix designs as they relate to Thailand's climatic conditions. Construction and Building Materials, 40, pp.961-970. 
[27] Charoentham, N. and Kanitpong, K. (2012). Development of Proposed Performance Grading System for Asphalt Binder used in Thailand. Asian Transport Studies, 2(2), pp.121-138.

[28] AASHTO (2009). Standard method of test for multiple stress creep recovery (MSCR) test of asphalt binder using a dynamic shear rheometer (DSR). American Association of State Highway and Transportation Officials, Washington, DC.

[29] AASHTO (2012). Standard method of test for determining the flexural creep stiffness of asphalt binder using the Bending Beam Rheometer (BBR)(AASHTO T313-12-UL). American Association of State Highway and Transportation Officials, Washington, DC.

[30] Anderson, R. M., King, G. N., Hanson, D. I., \& Blankenship, P. B. (2011). Evaluation of the relationship between asphalt binder properties and non-load related cracking. Journal of the Association of Asphalt Paving Technologists, 80 .

[31] McDaniel, R. S., \& Anderson, R. M. (2001). Recommended use of reclaimed asphalt pavement in the Superpave mix design method: technician's manual (No. Project D9-12 FY'97). National Research Council (US). Transportation Research Board.

[32] British Standard (2014). Bitumen and Bituminous binders Determination of resistance to hardening under influence of heat and air - part 1: RTFOT method. BS EN 12607-1. British Standards Institution, London, United Kingdom.

[33] British Standard (2000). Bitumen and bituminous binders - Accelerated long-term ageing conditioning by a Pressure Ageing Vessel (PAV), BS EN 14769:2012. British Standards Institution, London, United Kingdom.

[34]Marasteanu, M. O., \& Basu, A. (2004). Stiffness m-value and the low temperature relaxation properties of asphalt binders. Road materials and pavement design, 5(1), 121-131.

[35],Cuciniello, G., Leandri, P., Filippi, S., Presti, D. L., Losa, M., \& Airey, G. (2018). Effect of ageing on the morphology and creep and recovery of polymer-modified bitumens. Materials and Structures, 51(5), 136.

[36]Cuciniello, G., Leandri, P., Presti, D. L., Losa, M., \& Airey, G. (2019). Investigating the Effect of Artificial Ageing on the Creep and Recovery of SBS-Modified Bitumen. In MATEC Web of Conferences (Vol. 271, p. 03009). EDP Sciences.

[34]

[35][37] White, G. (2015). Grading of Australian bitumen by multiple stress creep recovery. Road and Transport Research, vol. 24, no. 4, pp.30-44

[36][38] White, G. (2016). Grading highly modified binders by multiple stress creep recovery. Road Materials and Pavement Design, 18(6), pp.1322-1337. 10.

[37][39] AASHTO. (2010). Standard specification for performance-graded asphalt binder using multiple stress creep recovery (MSCR) test. American Association of State Highway and Transportation Officials AASHTO designation: MP 19-10, Washington, D.C.

[38][40] Subhy, A., Presti, D. L., \& Airey, G. (2017). Evaluation of the fracture performance of different rubberised bitumens based on the essential work of fracture. Engineering Fracture Mechanics, 179, 203212.

[39][41] Agbovi, Henry Kwame (2012). Effects of low temperatures, repetitive stresses and chemical aging on thermal and fatigue cracking in asphalt cement pavements on highway 417. (M.Sc. Thesis). Queen's University Kingston, Ontario, Canada 
[42] Singh, D. and Girimath, S. (2016). Influence of RAP sources and proportions on fracture and low temperature cracking performance of polymer modified binder. Construction and Building Materials, 120, pp.10-18.

[43],Kataware, A. V., \& Singh, D. (2018). Evaluation of intermediate temperature cracking performance of warm mix additive modified asphalt binders. Construction and Building Materials, 184, 165-176.

[44]Paliukaite, M., Verigin, M., \& Hesp, S. (2015). Double-edge-notched tension testing of asphalt cement for the control of cracking in flexible asphalt pavements. Bituminous mixtures and pavements VI, 13.

[45] Singh, D., Girimath, S., \& Ashish, P. K. (2019). Effect of recycled asphalt binder on high and intermediate temperature performance of polymer modified asphalt binder. International Journal of Pavement Research and Technology, 12(5), 486-496.

[46] Kanabar, N. (2010). Comparison of ethylene terpolymer, styrene butadiene, and polyphosphoric acid type modifiers for asphalt cement (Doctoral dissertation). Queens University, Canada.

[47]Al-Mansob, R. A., Ismail, A., Alduri, A. N., Azhari, C. H., Karim, M. R., \& Yusoff, N. I. M. (2014). Physical and rheological properties of epoxidized natural rubber modified bitumens. Construction and Building Materials, 63, 242-248.

[48] Al-Mansob, R. A., Ismail, A., Md Yusoff, N. I., Azhari, C. H., Karim, M. R., Alduri, A., \& Baghini, M. S. (2014). Rheological characteristics of epoxidized natural rubber modified bitumen. In Applied Mechanics and Materials (Vol. 505, pp. 174-179). Trans Tech Publications Ltd.

[49]Usman, A., Izzaty, N., Ibrahim, R., Sutanto, M. H., \& Sunarjono, S. (2019). Storage Stability and Morphology of Latex Modified Bitumen. International Journal of Innovative and Exploring Engineering (IJITEE), ISSN, 2278-3075

[50] Biro, S., \& Fazekas, B. (2012). Asphalt rubber versus other modified bitumens. In The Asphalt Rubber 2012 Conference Proceedings, Munich (pp. 351-366).

[51]Porto, M., Caputo, P., Loise, V., Eskandarsefat, S., Teltayev, B., \& Oliviero Rossi, C. (2019). Bitumen and bitumen modification: A review on latest advances. Applied Sciences, 9(4), 742.

$[40]$
Formatted: Font: $10 \mathrm{pt}$

Formatted: Font: $10 \mathrm{pt}$

Formatted: Font: $10 \mathrm{pt}$

Formatted: Indent: Left: $0.25 "$, No bullets or numbering

Formatted: Font: $10 \mathrm{pt}$ 